\title{
Chapter 6 \\ Use of Pillared Clay-Based Catalysts \\ for Wastewater Treatment Through Fenton-Like \\ Processes
}

\author{
J. Herney-Ramírez and Luis M. Madeira
}

\begin{abstract}
Clays, both natural and physical-chemically modified, are attractive materials for the preparation of supported catalysts. In this chapter, a review is made regarding the use of pillared interlayered clays (PILCs) in heterogeneous Fentonlike advanced oxidation processes. Their applications in pollutants degradation is summarized, with particular emphasis on the effect of the main operating conditions (e.g., initial $\mathrm{H}_{2} \mathrm{O}_{2}$ or parent compound concentration, catalyst load, $\mathrm{pH}$, or temperature) on oxidation efficiency. Special attention is also given to the type of catalyst or precursor used, to the importance and advantages of the heterogeneous versus homogeneous process, and to significant aspects like catalyst stability. Among the technological issues that are of concern, the importance of using continuous flow reactors (e.g., fixed-bed) is discussed. Finally, some mechanistic studies are reviewed as well as modeling works, based on phenomenological or semi-empiric models (e.g., using statistic tools like design of experiments).
\end{abstract}

Keywords Pillared clays - Catalyst - Fenton - Wastewater treatment · Advanced oxidation processes

\subsection{Introduction}

\subsubsection{Water Treatment with Advanced Oxidation Processes}

Water and wastewater treatment is an issue of concern in our society. However, some of the typical treatment methods, for example, adsorption (e.g., using activated carbon), coagulation, or air stripping, simply transfer the aqueous organics

\footnotetext{
L.M. Madeira $(\bowtie)$

LEPAE, Department of Chemical Engineering, Faculty of Engineering, Porto University,

Rua Dr. Roberto Frias, 4200-465 Porto, Portugal

e-mail: mmadeira@fe.up.pt
} 
to another phase leaving the contaminants undestroyed. Moreover, many of these pollutants are refractory to biological degradation or even toxic to the microorganisms; when it is not the case, these processes proceed at low rates. Therefore, during the past decades many researchers have stressed their focus on searching for direct and effective methods to solve this problem.

Advanced oxidation processes (AOPs) are known as being effective to remove non-biodegradable organic pollutants from waters/wastewaters. Their efficiency results from the fact that the in situ generated hydroxyl radicals (HO-) are highly reactive species $\left(E^{\mathrm{O}}=+2.8 \mathrm{~V}\right)$, which attack the majority of the organic molecules causing their oxidation to other products and ultimately to $\mathrm{CO}_{2}$ and $\mathrm{H}_{2} \mathrm{O}$ [1], except for some of the simplest organic compounds such as acetic, maleic, and oxalic acids, acetone, or simple chloride derivatives as chloroform [2]. HO radicals attack the organic molecules with rate constants usually in the order of $10^{6}-10^{9} \mathrm{M}^{-1} \mathrm{~s}^{-1}$ [3]. They are also characterized by a low selectivity of attack, which is a useful attribute for an oxidant used in wastewater treatment and for solving pollution problems [4]. The radicals are produced by processes that usually operate at mild temperatures and pressures and that result from the combinations of ozone, hydrogen peroxide, UV radiation, ferrous ions and/or titanium dioxide, among others (see Fig. 6.1). Contaminants are mainly oxidized through the use of four different reagents: ozone, hydrogen peroxide, oxygen, and air or their combination. To choose the most appropriate technology some aspects, such as the concentration and nature of the pollutants and the volume of wastewater, must be considered [5].
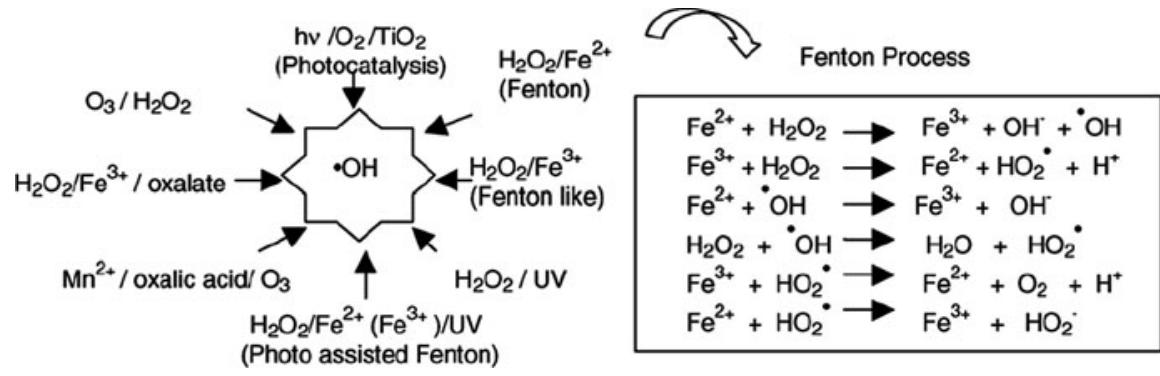

Fig. 6.1 Sketch of some advanced oxidation processes. Reprinted from [1], with permission from Elsevier

The versatility of the AOPs is also enhanced by the fact that they offer different possible ways for hydroxyl radicals production, thus allowing a better compliance with the specific treatment requirements, as described by Andreozzi et al. [3]. Currently, the four AOPs that have been most widely studied are ozonation, $\mathrm{H}_{2} \mathrm{O}_{2} / \mathrm{UV}$, the Fenton's reagent $\left(\mathrm{Fe}^{2+} / \mathrm{H}_{2} \mathrm{O}_{2}\right)$, and $\mathrm{TiO}_{2} / \mathrm{UV}$ [6]. AOPs include also other techniques, such as methods based on ultrasound, plasma, and electrohydraulic, among others, but are much less common [5]. In this chapter we will focus our attention on the use of Fenton-like processes, also often called wet hydrogen peroxide catalytic oxidation (WHPCO) or catalytic wet peroxide oxidation (CWPO), for instance. Actually, hydrogen peroxide is one of the more desirable 
oxidant agents; although $\mathrm{H}_{2} \mathrm{O}_{2}$ is a relatively costly reactant, it is easy to handle and the excess decomposes to environmentally safe products. Besides, as compared with ozone, for instance, it does not form any harmful by-products and is a non-toxic and ecological reactant [7]. Advantages of Fenton's reagent over other oxidizing treatment methods include also the high efficiency, simplicity in destroying the contaminants (eventually leaving no residues), stability to treat a wide range of substances, and non-necessity of special equipment. Besides, operating conditions are usually mild (atmospheric pressure and around room temperature), and the reaction rates are reasonably high due to the use of the iron catalyst.

As described in detail below, the use of this AOP aims usually at the degradation of certain compounds or complex wastewaters to meet the environmental standards before effluent's discharge. Nevertheless, its use has been often considered when coupled with biological processes. Actually, integrated catalytic-biological systems have been recently seen as cost-effective processes for the treatment of organic compounds and have become an important developing trend in practical industrial wastewater treatment. This is due to the fact that compared with typical biological treatment, AOPs such as Fenton-like normally have a much higher operating cost. Therefore, in a real industrial wastewater treatment plant, complete mineralization of the wastewater by AOPs is not cost-effective and not necessary. So, to decrease the operational cost, the use of AOPs as a pre-treatment step to enhance the biodegradability of wastewater containing recalcitrant or inhibitory compounds is an interesting approach if the resulting intermediates are easily degradable in a further biological unit. Based on this idea, the Fenton reactors can be envisaged as the pre-treatment step of wastewaters.

\subsubsection{The Use of Pillared Clays in Heterogeneous Fenton-Based Processes}

Fenton-like processes have been traditionally employed in a homogeneous way, i.e., with the iron catalyst salt dissolved in the aqueous solution. However, there is a major drawback: they need large amounts of Fe in solution (up to 50-80 ppm), which is well above the EU directives that allow a maximum of $2 \mathrm{ppm}$ Fe in treated water to be discharged directly into the environment [8]. In addition, the application of the homogeneous treatment to large water flow rates may produce large amounts of sludge in the final neutralization step. The treatment of the sludge-containing Fe ions at the end of wastewater treatment (usually through precipitation and redissolution) is costly and needs large amount of chemicals and manpower [9].

Therefore, numerous attempts have been done to find heterogeneous systems/supports for the Fe species, so that they can be effectively applied in wastewater treatment, e.g., see Refs. [10-15]. The major advantage of the use of heterogeneous catalytic materials is their easy recovery. Unlike the homogeneous systems, these solid catalysts can be recuperated by means of a simple separation operation and re-used in the next runs. Besides, these materials should meet criteria 
like high efficiency/catalytic activity, low cost, and long-term stability. In this sense, one of the principal goals is the development of stable heterogeneous catalysts with minimal leaching of the active species under the reaction conditions. Studies found in the literature refer to the use of membranes (e.g., Nafion-based), resins, zeolites, silica, alumina, or carbons. Here, we are particularly concerned with pillared clays, which have several advantages as extensively described in other chapters of this book, namely, their particular properties and structures as well as their abundance and low cost.

Clays have been widely used as ion exchangers, catalysts, and adsorbents. However, the lack of permanent high porosity limits their further application in industry [16]. To solve this problem, bulky inorganic polycations obtained from polymerization of multivalent inorganic cations (e.g., $\mathrm{Al}^{3+}, \mathrm{Zr}^{4+}, \mathrm{Ti}^{4+}$, and $\mathrm{Fe}^{3+}$ ) have been intercalated into the interlayer region of the clays by cationic exchange [17-19]. This is done because when clays are dispersed in water, they swell significantly owing to the hydration of the interlamellar cations that act as counter ions to balance the negative charges of the clay layers [9]. Therefore, polycations in aqueous solutions can be intercalated into the interlayer gallery by cation exchange. The intercalated polycations increase the basal spacing of the clays and, upon heating in the calcination stage at a high temperature, the intercalated species undergo dehydration and dehydroxylation and hence are converted to temperature-stable oxide pillars, propping the clay layers apart and preventing its collapse. The final pillared interlayered clays (PILCs) present a permanent two-dimensional porous network, showing a dramatic improvement in catalytic and adsorption applications $[17,18]$. The final properties of PILCs can be modulated by carefully choosing the different parameters, such as nature of the pillaring agent, type of clay and particle size, pillaring procedure, and thermal treatments, thus offering a very powerful and flexible way to design tailored catalysts. Therefore, control of the pillaring process is a very promising means to obtain solids with (i) very high surface areas up to $600 \mathrm{~m}^{2} \mathrm{~g}^{-1}$, (ii) a broad spectrum of properties (structural, chemical, catalytic, etc.), and (iii) controlled internal structures, with reactive sites and/or species chosen to match particular applications or provide host structures for chemical or physical processes $[20,21]$.

Actually, PILCs constitute one of the most widely studied materials among the new groups of microporous materials developed by molecular engineering. An extensive review on the advances in the synthesis and catalytic applications of PILCs (also known as cross-linked clays) has been published by Gil et al. [18]. One of the more studied topics related to PILCs is their use as support for active catalytic phases in the preparation of supported catalysts and the applicability of the resulting solids in several reactions, particularly environmental-friendly ones [22].

Among the intercalated clay precursors indicated above, $\mathrm{Fe}^{3+}$ is an ongoing one for research in heterogeneous catalysis and adsorption, being of particular relevance in Fenton-based processes which make use of Fe species as catalyst.

Several studies on the formation of Fe-PILC were carried out in the past few years, as stated by Sum et al. [16]. In particular, many researchers showed that when using bentonite and montmorillonite clays, the Fe-PILC has basal spacings of up to 
10-20 $\AA$ and BET surface area reaching up to $300 \mathrm{~m}^{2} / \mathrm{g}$ [16]. Montmorillonites in particular constitute one of the most abundant smectitic clays in nature [23]. They are characterized by the substitution of $\mathrm{Al}^{3+}$ by $\mathrm{Mg}^{2+}$ in the octahedral sheet, resulting in a negative layer charge that is compensated by hydrated cations adsorbed in the interlamellar space. These cations can be easily substituted by others present in solution.

Another interesting material for the applications envisaged in this review is laponite. As described by Bobu et al. [17], in a diluted aqueous dispersion laponite $\mathrm{RD}$ (model synthetic hectorite-type smectite clay) exists as discrete plates with 20-30 nm diameter. Therefore, this clay is an ideal inorganic medium to form nanometer-scale composite structures with iron oxide particulates named Fe-LapRD. X-ray diffraction results revealed that the Fe-Lap-RD mainly consists of $\mathrm{Fe}_{2} \mathrm{O}_{3}$ (maghemite) crystallites and $\mathrm{Fe}_{2} \mathrm{SiO}_{10}(\mathrm{OH})_{2}$ (iron silicate hydroxide) crystallites.

As described by Iurascu et al. [24], Fe has also been often incorporated by pillaring of smectites, yet polymerization of $\mathrm{Fe}(\mathrm{III})$ produces polyoxocations that can intercalate swellable clays by substitution of their exchangeable cations. However, intercalation pillaring with $\mathrm{Fe}$ has a main disadvantage because it is not easily reproducible. Differently from the $\mathrm{Al}_{13}$ polycation, well known and easy to prepare, $\mathrm{Fe}$ forms various polycations depending on the preparation conditions. Thus, some authors, including the present ones [25, 26] and others, e.g., see Ref. [24], have used a new strategy for the preparation of Fe-clay catalysts, which involves the impregnation with Fe-salts of previously prepared Al-pillared saponite. In this way, the textural properties of the support are maintained, because of the high stability of Al-pillared saponite, and the amount of the Fe-active phase can easily be controlled.

\subsubsection{Pollutants Degraded or Wastewaters Treated with Pillared Clay-Based Catalysts}

As mentioned before, PILCs have been extensively used in Fenton-like processes. Table 6.1 provides an overview of the pollutants degraded by such processes and the types of PILCs used. Among the different types of substances degraded using this AOP, phenols (and their derivatives) deserved the attention of numerous studies. Actually, phenols are among the most abundant pollutants in industrial wastewaters, due to their wide utilization in several industries. The world production of phenol is estimated to be over $3 \times 10^{6}$ t/year [24], being used in the synthesis of resins, dyes, pharmaceuticals, perfumes, pesticides, tanning agents, solvents, or lubricating oils. It has several concerns to human health, as long-term exposure to phenol paralyzes the central nervous system and damages kidneys and lungs. Besides, biodegradability is only $90 \%$ in surface waters after 7 days, and the aquatic toxicity of phenol $\left(\mathrm{LC}_{50}\right.$ ) is $12 \mathrm{mg} / \mathrm{l}$ (Daphnia magna, $48 \mathrm{~h}$ ) [24].

Another class of compounds that has been widely covered in the literature and reported in Table 6.1 is dyes. Over 700,000 $\mathrm{t}$ of approximately 10,000 types of dyes and pigments are produced every year worldwide [27]. From this amount, about 
Table 6.1 Some examples of substances degraded by Fenton-like processes using pillared clays

\begin{tabular}{lll}
\hline Type of pollutant degraded & Type of pillared clay & References \\
\hline Phenol & Pillared bentonite containing iron & {$[32-35]$} \\
Phenol & Fe-exchanged pillared beidellite & {$[36]$} \\
4-Nitrophenol & Fe-modified montmorillonite & {$[37]$} \\
Azo-dye Orange II & Saponite clay-based catalyst & {$[25,26]$} \\
Azo-dye Reactive Yellow 84 & Iron-containing pillared beidellite & {$[38]$} \\
Cinnamic acid & Fe-pillared montmorillonite & {$[30]$} \\
\hline
\end{tabular}

$20 \%$ are discharged without treatment [28]. So, the disposal of the large amounts of effluents from textile industry produces uncontrollable environmental hazards because they contain considerable color as well as appreciable quantities of organic compounds that are not easily eliminated by conventional wastewater treatment methods (particularly azo dyes due to their non-biodegradable nature or toxicity) $[6,27,29]$.

Finally, cinnamic acids [30], which are simple aromatic compounds that result from olive cell wall degradation during oil extraction, were studied using Fe-pillared montmorillonite catalyst (see Table 6.1). These various aromatic acids are typically found in wastewaters of agricultural origin and represent a dangerous contamination. The conventional biological or physico-chemical treatments are slow or non-destructive and consequently are considered as inadequate for eliminating these types of pollutants. Attempts to develop an appropriate technology based on partial oxidation using ozone as oxidant or by applying wet air oxidation have been reported. However, these methods are considered to be either expensive or requiring a high reaction temperature [31] and so the Fenton-like might be a feasible alternative.

In the following section, we will describe this AOP in more detail, with special emphasis on the effect of the operating conditions, as well as on other technological issues that are of concern for real implementation.

\subsection{Fenton and Fenton-Like Process}

\subsubsection{Introduction}

In 1894 , Fenton reported that ferrous ion strongly promotes the oxidation of tartaric acid by hydrogen peroxide [39]. Forty years later, Haber and Weiss [40] discovered that the hydroxyl radical is the actual oxidant in such system. In reality, the Fenton catalyst $\left(\mathrm{Fe}^{2+} / \mathrm{Fe}^{3+}\right.$ system) causes the dissociation of hydrogen peroxide and the formation of highly reactive HO radicals that attack and destroy the organic compounds. This reaction is a widely used and studied catalytic process based on an electron transfer between $\mathrm{H}_{2} \mathrm{O}_{2}$ and a metal (usually transition metal) acting as 
a homogeneous catalyst [41, 42]. By far, the most common of these ones is iron $[43,44]$.

The mechanism of Fenton's oxidation involves basically the following steps. First, a mixture of $\mathrm{H}_{2} \mathrm{O}_{2}$ and ferrous iron in acidic solution generates hydroxyl radicals according to the following reaction [44-47]:

$$
\mathrm{Fe}^{2+}+\mathrm{H}_{2} \mathrm{O}_{2} \rightarrow \mathrm{Fe}^{3+}+\mathrm{HO}^{-}+\mathrm{HO}^{\bullet}, k_{1}=51-100 \mathrm{M}^{-1} \mathrm{~s}^{-1}
$$

Because iron(II) acts as a catalyst, it has to be restored, which seems to occur through the following scheme:

$$
\begin{gathered}
\mathrm{Fe}^{3+}+\mathrm{H}_{2} \mathrm{O}_{2} \leftrightarrow \mathrm{Fe}-\mathrm{OOH}^{2+}+\mathrm{H}^{+}, k_{2}=0.001-0.01 \mathrm{M}^{-1} \mathrm{~s}^{-1} \\
\mathrm{Fe}-\mathrm{OOH}^{2+} \rightarrow \mathrm{Fe}^{2+}+\mathrm{HO}_{2}^{\bullet}
\end{gathered}
$$

The reaction of hydrogen peroxide with ferric ions is referred to as a Fenton-like, see reactions (6.2) and (6.3) [48, 49].

The generation of the radicals involves a complex reaction sequence in aqueous solution, some of them described below. In particular, it is worth noting the scavenging of different radicals by the Fe species and also by $\mathrm{H}_{2} \mathrm{O}_{2}$, which can act as an $\mathrm{OH} \cdot$ scavenger as well as an initiator (reaction (6.1)).

$$
\begin{gathered}
\mathrm{Fe}^{2+}+\mathrm{HO}^{\bullet} \rightarrow \mathrm{Fe}^{3+}+\mathrm{HO}^{-}, k_{4}=3-4.3 \times 10^{8} \mathrm{M}^{-1} \mathrm{~s}^{-1} \\
\mathrm{Fe}^{2+}+\mathrm{HO}_{2}^{\bullet} \rightarrow \mathrm{Fe}^{3+}+\mathrm{HO}_{2}^{-}, k_{5}=1.3 \times 10^{6} \mathrm{M}^{-1} \mathrm{~s}^{-1} \\
\mathrm{Fe}^{3+}+\mathrm{HO}_{2}^{\bullet} \rightarrow \mathrm{Fe}^{2+}+\mathrm{O}_{2}+\mathrm{H}^{+}, k_{6}=1.2 \times 10^{6} \mathrm{M}^{-1} \mathrm{~s}^{-1} \\
\mathrm{H}_{2} \mathrm{O}_{2}+\mathrm{HO}^{\bullet} \rightarrow \mathrm{HO}_{2}^{\bullet}+\mathrm{H}_{2} \mathrm{O}, k_{7}=1.2-4.5 \times 10^{7} \mathrm{M}^{-1} \mathrm{~s}^{-1}
\end{gathered}
$$

It is finally worth noting that the scheme presented herein is a simplification of those reported by several authors, where tens of equations are often considered $[2,50]$.

Hydroxyl radicals formed can then oxidize organics $(\mathrm{RH})$ by abstraction of protons producing organic radicals $(\mathrm{R} \cdot)$, which are highly reactive and can be further oxidized [51, 52]:

$$
\mathrm{RH}+\mathrm{HO}^{\bullet} \rightarrow \mathrm{R}^{\bullet}+\mathrm{H}_{2} \mathrm{O} \rightarrow \text { Further oxidation }
$$

Walling [44] simplified the overall Fenton chemistry (reaction (6.1)) by accounting for the dissociation water:

$$
2 \mathrm{Fe}^{2+}+\mathrm{H}_{2} \mathrm{O}_{2}+2 \mathrm{H}^{+} \rightarrow 2 \mathrm{Fe}^{3+}+2 \mathrm{H}_{2} \mathrm{O}
$$


This equation suggests that the presence of $\mathrm{H}^{+}$is required in the decomposition of $\mathrm{H}_{2} \mathrm{O}_{2}$, indicating the need for an acid environment to produce the maximum amount of hydroxyl radicals.

The oxidation using Fenton's reagent has proved to be a promising and attractive treatment method for the effective destruction of a large number of hazardous and organic pollutants, e.g., see Refs. [2, 3]. However, and as mentioned above (see Section 6.1.2), the homogeneous Fenton process often needs significant amounts of the metal in solution, increasing the subsequent costs for sludge's treatment and/or catalyst recovery. So, recent research trends have been focused on the incorporation of the $\mathrm{Fe}$ ions or Fe oxides into porous supports, particularly into PILCs for the reasons described above (cf. Section 6.1.2), namely, their particular properties and structures (with tunable pore size), as well as the abundance and low cost of natural clay minerals. Besides, they lead to active and stable solids in aqueous media, usually being very stable against leaching [38].

Table 6.2 gives a perspective of some of the studies found in the open literature in which PILCs have been employed in the Fenton/Fenton-like degradation of some compounds. The best or typical performances reached are also mentioned, as well as the corresponding operating conditions. In this concern it is important to remark that in most studies not only information on the parent compound degradation is gathered, but also information on mineralization (i.e., quantification of total organic carbon - TOC - reduction) is also of crucial importance. Actually, even if the complete degradation can be achieved, some intermediates might still be formed having eventually a higher toxic potential than the parent compound. Thus, in Table 6.2, data about TOC conversion are also included, whenever available.

\subsubsection{Effect of the Main Operating Conditions}

The heterogeneous Fenton-like process is affected by several process parameters. This will be discussed in the following sections, and some examples will be given to better illustrate such effects.

\subsubsection{Effect of the Initial $\mathrm{pH}$}

A dependence of the reaction performance with the $\mathrm{pH}$ is normally observed in homogeneous and heterogeneous Fenton-like reactions. In homogeneous systems the decreased performance at lower $\mathrm{pHs}$ is usually attributed to the inhibition of the reaction between $\mathrm{Fe}^{3+}$ and hydrogen peroxide (reaction (6.2)), because the formation of the iron(III) peroxocomplexes (as intermediates) decreases when $\mathrm{pH}$ decreases [55]. Besides, at $\mathrm{pH}$ around 3.0 maximum concentration of the active $\mathrm{Fe}^{2+}$ species is reached along with the lowest rate of $\mathrm{H}_{2} \mathrm{O}_{2}$ parasitic decomposition. By increasing the $\mathrm{pH}$, the precipitation of the insoluble ferric hydroxides takes place and the decomposition of $\mathrm{H}_{2} \mathrm{O}_{2}$ becomes significant [35]. This disadvantage can be avoided using a heterogeneous system; for example, Catrinescu et al. [36] observed that although an important difference in phenol removal in the $2.5-7.0 \mathrm{pH}$ 


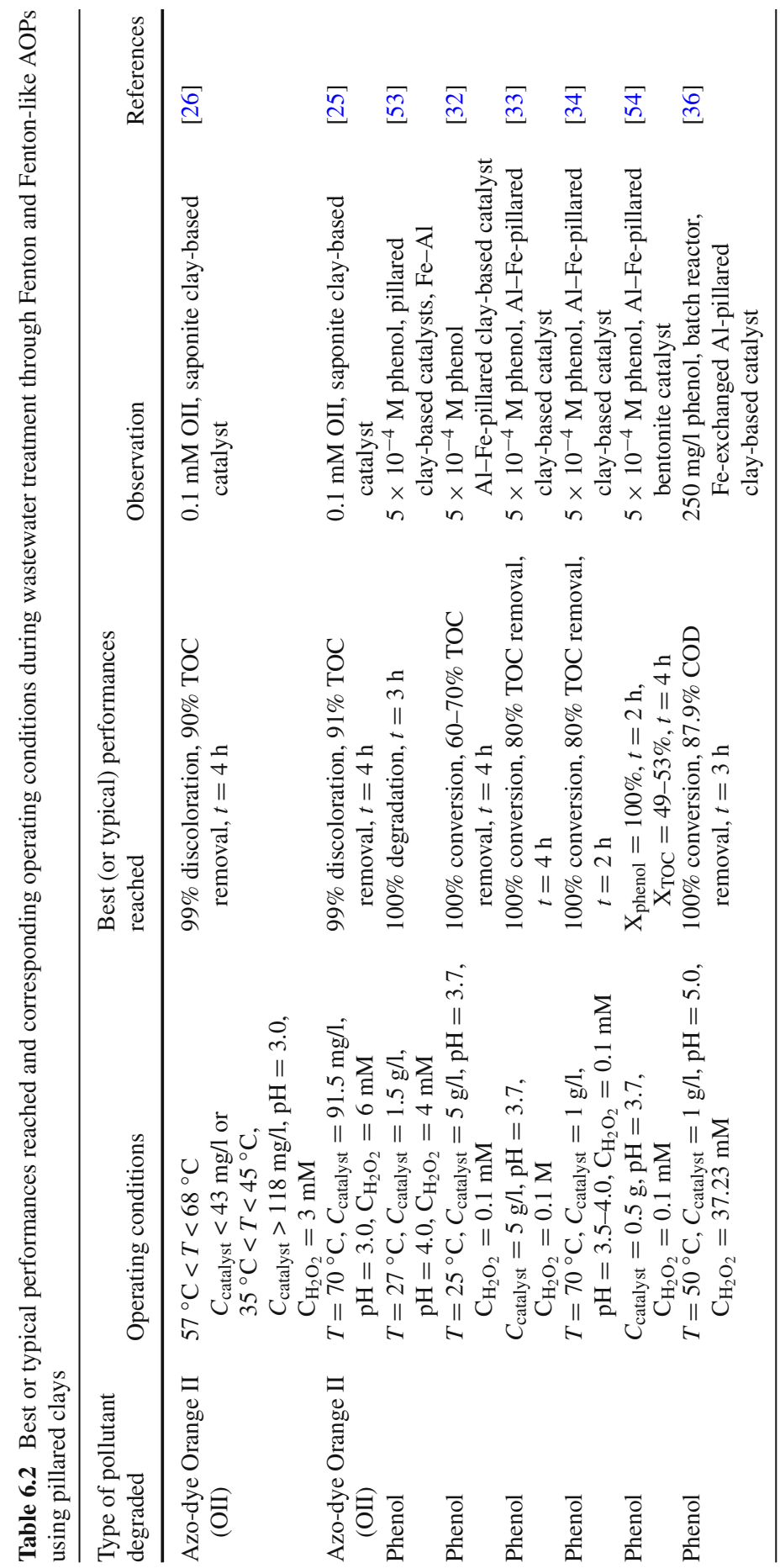




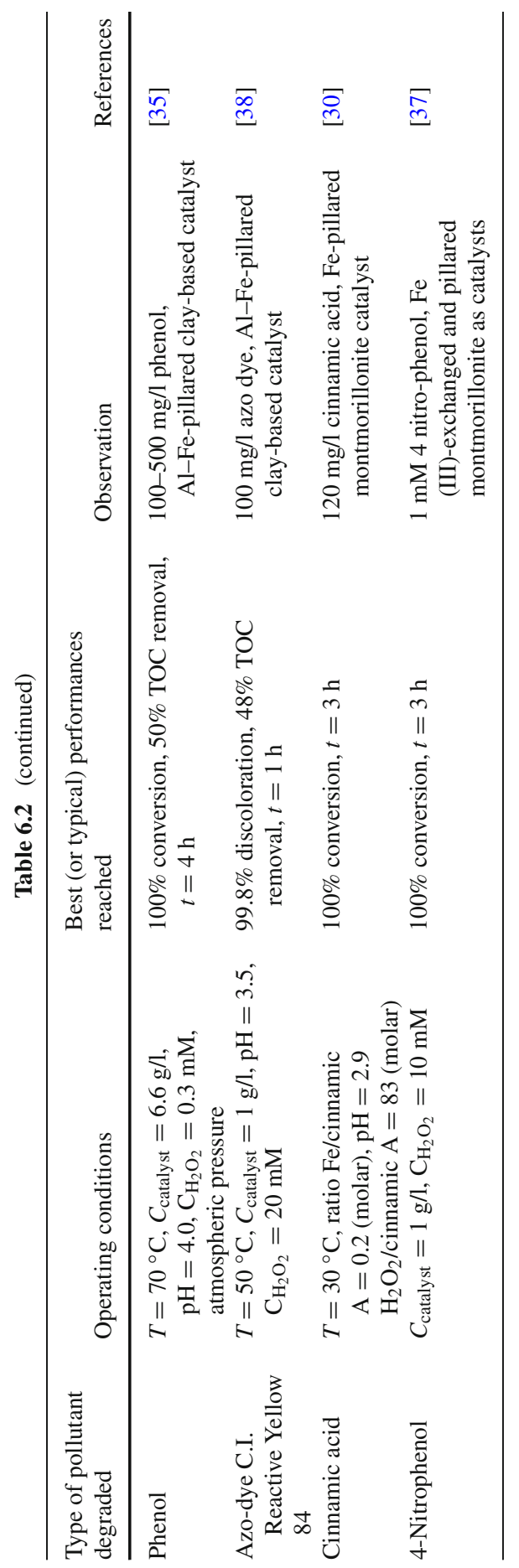


Fig. 6.2 Phenol removal at different $\mathrm{pH}$ values

$\left(C_{\text {PILC catalyst }}=0.5 \mathrm{~g} / \mathrm{l}\right.$,

$C_{\mathrm{Pho}}=250 \mathrm{ppm}$;

$\mathrm{C}_{\mathrm{H}_{2} \mathrm{O}_{2}}=37.23 \mathrm{mM}$,

$T=50^{\circ} \mathrm{C}$ ). Reprinted from

[36], with permission from

Elsevier

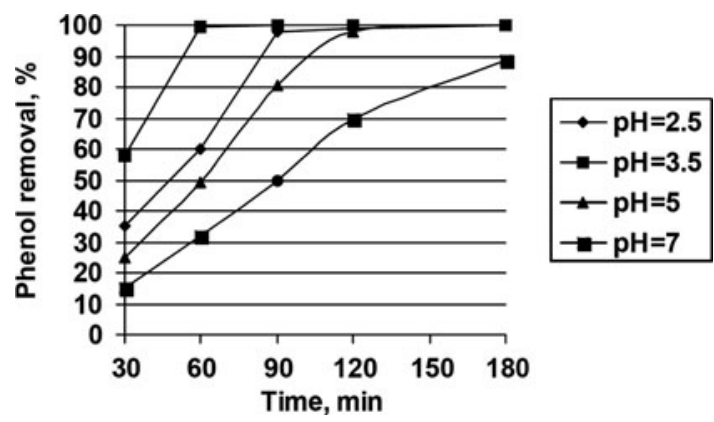

range occurs for initial reaction times, this is attenuated after ca. $2 \mathrm{~h}$, at least for $\mathrm{pH}$ values up to 5 (see Fig. 6.2). Besides, when $\mathrm{Fe}^{3+}$-exchanged Al-pillared beidellite is used, intermediates are completely eliminated, whatever be the $\mathrm{pH}$ value within the 2.5-5.0 range. The catalyst remains active even at neutral $\mathrm{pH}$. This is in contrast to homogeneous Fenton catalysts which show no, or negligible, activity at this $\mathrm{pH}$. This activity could be related to the particular environment of $\mathrm{Fe}$ cations inside the pore structure of PILCs, where strong electrostatic fields are present [36]. Accordingly, by using heterogeneous catalysts, such as PILCs, it is possible to extend the range of $\mathrm{pH}$ values for which Fenton-type oxidation can occur.

Other authors, using pillared clay catalyst for phenol conversion [32], found that the stability of hydrogen peroxide is dependent on $\mathrm{pH}$. The least decomposition of $\mathrm{H}_{2} \mathrm{O}_{2}$ was found at $\mathrm{pH}$ values between 3 and 4. This range corresponds to the highest stability zone of $[\mathrm{Fe}(\mathrm{OH})]^{2+}$. Above $\mathrm{pH} 4$, the rapid hydrogen peroxide decomposition produces molecular oxygen without formation of appreciable amounts of hydroxyl radicals in the solution. Below pH 3, more of the charged ferric ions remained as hydrated ferric ions, which accelerate not only the decomposition of the peroxide but also the competitive reaction for hydroxyl radicals' depletion. In addition, a pH lower than 3 favors leaching of the metal into the solution [35].

Other studies have also reported optimum $\mathrm{pH}$ values close to 3-4 in heterogeneous PILC-based systems, for instance, Tatibouët et al. [32] during phenol conversion or Ramirez et al. [25] during Orange II dye degradation. In another study [30], using Fe-pillared clay as a Fenton-type heterogeneous catalyst for cinnamic acid degradation, the $\mathrm{pH}$ varied between 2.9 and 5.0. Figure 6.3 shows that a lower $\mathrm{pH}$ led to a higher removal, both in homogeneous and heterogeneous systems. From Fig. 6.3 it can be seen that the heterogeneous Fenton reagent was more efficient than the homogeneous one in reducing concentration of cinnamic acid, the difference being particularly noticeable at $\mathrm{pH}$ 5. It might be the result of the affinity of the organic species for the clay surface. Furthermore, the heterogeneous catalyst activity was slightly less sensitive than that of the homogenous catalyst to $\mathrm{pH}$ variations in the 2.9-5.0 range after $3 \mathrm{~h}$, while during the first $2 \mathrm{~h}$ the sensitivity in the two cases was similar. In this study, a higher elimination rate of cinnamic acid was obtained at $\mathrm{pH}=2.9$. 


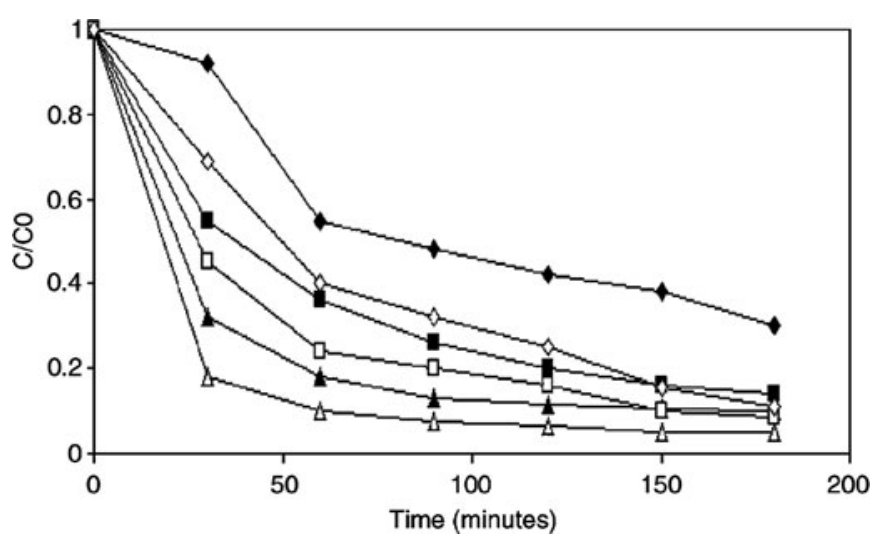

Fig. 6.3 Influence of the $\mathrm{pH}$ on the disappearance of cinnamic acid as a function of time at various pHs at $\mathrm{Fe} /$ cinnamic acid molar ratio $=10$ and $\mathrm{H}_{2} \mathrm{O}_{2}$ /cinnamic acid molar ratio $=8.3$. Solid symbols refer to homogeneous catalysis and open symbols to heterogeneous catalysts: $(\diamond) \mathrm{pH}=5.0,(\square)$ $\mathrm{pH}=4.0$, and $(\Delta) \mathrm{pH}=2.9$. Reprinted from [30], with permission from Elsevier

\subsubsection{Effect of the Temperature}

Temperature is a very important parameter in the Fenton and Fenton-like processes, because it can affect not only the catalytic performance but also the stability of the hydrogen peroxide (and eventually of the catalyst, by acting on the leaching). Several researchers have investigated the effect of temperature on the degradation/conversion of different compounds, using PILCs. For instance, Ramirez et al. [26] have used a clay-based Fenton-like catalyst for the oxidation of Orange II and found that the reaction temperature has indeed an important effect on the dye degradation history. Total color removal can be reached in less than 30 min when working at a temperature of $73.6{ }^{\circ} \mathrm{C}$ (Fig. 6.4a), but at lower temperatures the process slows down significantly. This kind of effect was expected, since it is known that kinetic constants (either for radicals production or for iron regeneration) have exponential dependency with reaction temperature (Arrhenius law). For TOC removal (Fig. 6.4b) the same kind of effect can be seen as for dye degradation. Temperature increase leads to better TOC removal, but the difference between temperatures of 40 and $73.6{ }^{\circ} \mathrm{C}$ is not as significant as it was observed for color removal. This is probably due to the fact that $\mathrm{H}_{2} \mathrm{O}_{2}$ decomposes into oxygen and water at high temperatures, affecting more strongly mineralization of all of the organics which proceed more slowly (and thus the effect is noticed at longer reaction times) than OII degradation. Similar trends were obtained by other authors [35, 36]. Finally, when the temperature increases the iron loss from the support also increases, affecting the stability of the catalyst (cf. Fig. 6.4c).

Guélou et al. [33] observed that when they changed the temperature between 18 and $70{ }^{\circ} \mathrm{C}$, an increase, both in the rate of phenol conversion and in the TOC abatement level, was reached. The study carried out by Barrault et al. [34] over mixed (Al-Fe)-pillared clays showed results very similar to the ones obtained by 

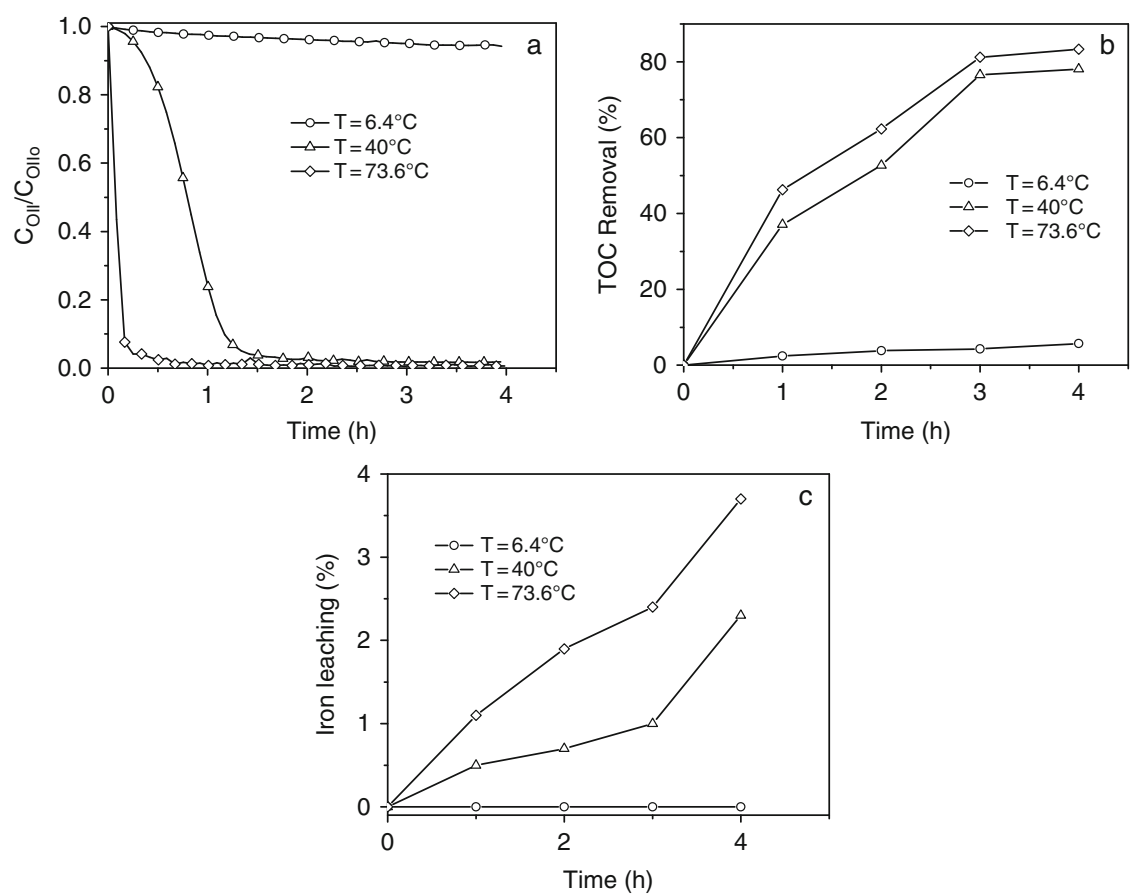

Fig. 6.4 Temperature effect on Orange II dye degradation (a), mineralization (b), and iron loss (c); $C_{\text {catalyst. }}=70 \mathrm{mg} / \mathrm{l}, \mathrm{C}_{\mathrm{H}_{2} \mathrm{O}_{2}}=1.3 \times 10^{-2} \mathrm{M}, \mathrm{pH}=3$. Reprinted from [26], with permission from American Chemical Society

Guélou et al. [33]. It should be noticed that the catalyst leaching remains low, but in this case the effect of the temperature was the opposite to that reported in Fig. 6.4c ( 0.8 and $0.2 \mathrm{ppm}$ after $4 \mathrm{~h}$ of reaction at 40 and $70{ }^{\circ} \mathrm{C}$, respectively).

\subsubsection{Effect of the Initial $\mathrm{H}_{2} \mathrm{O}_{2}$ Concentration}

Luo et al. [53] determined that when changing the hydrogen peroxide concentration between 1.1 and $4.1 \mathrm{mM}$ for phenol degradation, no significant effect was observed. Guélou et al. [33] also found that, for the oxidation of phenol but in a semi-continuous reactor, for a reaction time less than $60 \mathrm{~min}$ the rate of the addition of the hydrogen peroxide seems to have no important effect on the rate of phenol conversion, except for the lowest flow rate used. However, the total phenol conversion is reached for increasing times when the load of hydrogen peroxide solution decreases (Fig. 6.5). The same effect was observed for the TOC abatement, but the maximum value reached after more than $4 \mathrm{~h}$ of reaction remains about the same $(\approx 80 \%)$, whatever the concentration/flow-rate of the hydrogen peroxide solution.

Guo and Al-Dahhan [35] studied the catalytic wet oxidation of phenol by hydrogen peroxide over PILCs, also continuously adding the oxidant to minimize its 
Fig. 6.5 Influence of the hydrogen peroxide addition rate on the phenol conversion $\left(T=70^{\circ} \mathrm{C}\right.$, catalyst $=$ $10 \mathrm{~g} / \mathrm{l}) ;(\bullet) 4 \times 10^{-4} \mathrm{~mol} / \mathrm{h}$, (ロ) $2 \times 10^{-4} \mathrm{~mol} / \mathrm{h},(\mathbf{\Delta})$ $1.6 \times 10^{-4} \mathrm{~mol} / \mathrm{h},(\mathbf{\nabla})$ $1 \times 10^{-4} \mathrm{~mol} / \mathrm{h}$. Reprinted from [33], with permission from Elsevier

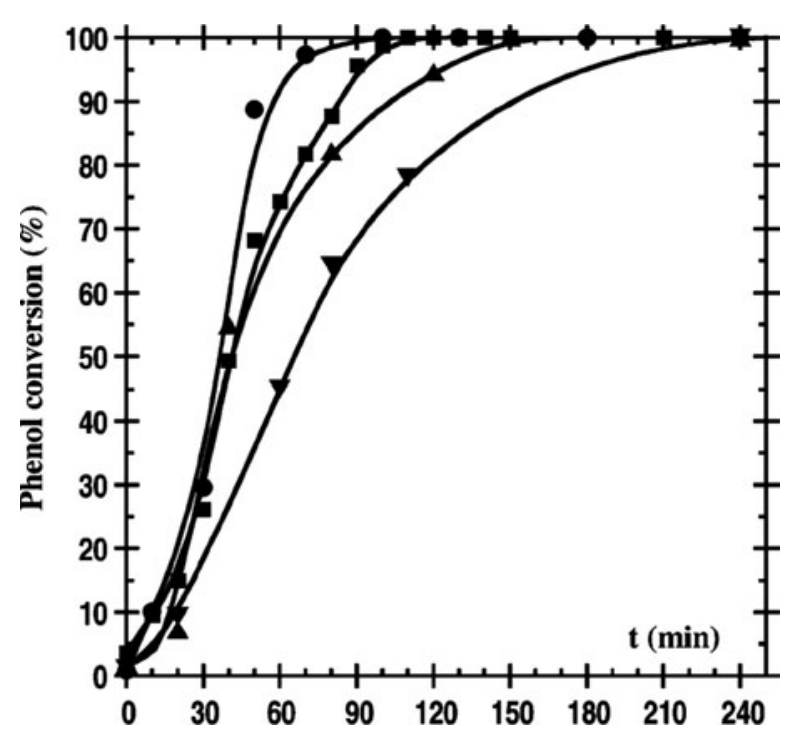

consumption and to maximize the efficiency of its use. In such a work, the authors have shown the time dependence of phenol conversion at four $\mathrm{H}_{2} \mathrm{O}_{2}$ concentrations, corresponding to about $25,50,100$, and $600 \%$ of the stoichiometric amount required for complete removal of aqueous phenol at $180 \mathrm{~min}$. A higher initial rate of phenol removal results from a higher $\mathrm{H}_{2} \mathrm{O}_{2}$ concentration, which means that the $\mathrm{H}_{2} \mathrm{O}_{2}$ concentration needs to be considered in their kinetic expressions.

Ramirez et al. [25], in the Fenton-like oxidation of Orange II solutions using catalysts based on saponite clay, have also varied the hydrogen peroxide concentration between 3 and $24 \mathrm{mM}$. It was observed that the increase of the oxidant concentration from 3 to $12 \mathrm{mM}$ leads to an increase in the reaction rate, as expected, because more radicals will be formed. Nevertheless, for a very high hydrogen peroxide concentration $(24 \mathrm{mM})$ the performance decreases (Fig. 6.6). The existence of an optimum hydrogen peroxide concentration is typical and well known in Fenton's oxidation. At higher $\mathrm{H}_{2} \mathrm{O}_{2}$ concentrations the scavenging of $\mathrm{HO}$. radicals will occur, which can be expressed by reaction (6.7). Although other radicals $\left(\mathrm{HO}_{2} \cdot\right)$ are produced, their oxidation potential is much smaller than that of the HO- species.

The existence of optimum oxidant doses has also been reported in other works [30], putting into evidence the need of a careful design to optimize process efficiency.

\subsubsection{Effect of the Catalyst Load}

Luo et al. [53] in phenol oxidation with a $\mathrm{Fe}-\mathrm{Al}$-pillared clay by $\mathrm{H}_{2} \mathrm{O}_{2}$ found an increase in the reaction rate when the catalyst concentration was increased, but only up to a certain load after which it becomes less efficient (Fig. 6.7). 


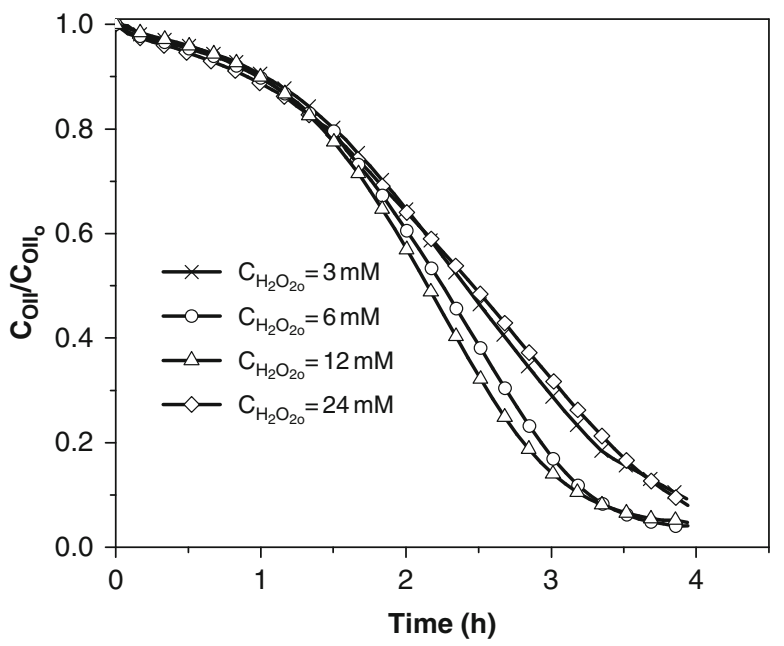

Fig. 6.6 Effect of the hydrogen peroxide concentration on the degradation of OII solution using $\mathrm{Fe}$ (II) oxalate 7.5 catalysts; $\mathrm{pH}=3, T=30^{\circ} \mathrm{C}$. Reprinted from [25], with permission from Elsevier

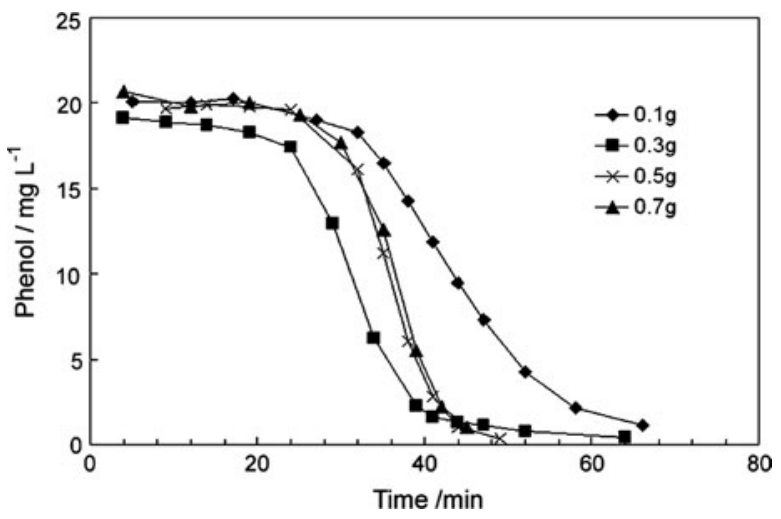

Fig. 6.7 Effect of amount of catalyst on phenol abatement. Experimental conditions: phenol 19-21 mg/l, $\mathrm{H}_{2} \mathrm{O}_{2}=4 \mathrm{mM}, T=28 \pm 1{ }^{\circ} \mathrm{C}$, and $\mathrm{pH}=4.0 \pm 0.1$. Reprinted from [53], with permission from Elsevier

Other authors [34, 36] observed a similar behavior; Catrinescu et al. [36] studied a range of PILC catalyst concentrations between 0 and $1 \mathrm{~g} / \mathrm{l}$. Figure 6.8 shows that the chemical oxygen demand (COD) removal depends on the catalyst concentration for up to $0.5 \mathrm{~g} / \mathrm{l}$. By further increasing the amount of catalyst to $1 \mathrm{~g} / \mathrm{l}$, only a slight increase in the phenol removal and COD removal efficiency was reached. So, for the given phenol concentration, there is an optimum concentration for the PILC, which could be situated around $0.5 \mathrm{~g} / \mathrm{l}$. 
Fig. 6.8 Influence of the catalyst concentration on COD removal: $250 \mathrm{mg} / 1$ phenol, $50^{\circ} \mathrm{C}$, initial $\mathrm{pH}=3.5$,

$\mathrm{H}_{2} \mathrm{O}_{2}=37.23 \mathrm{mM}, 120 \mathrm{~min}$. Reprinted from [36], with permission from Elsevier
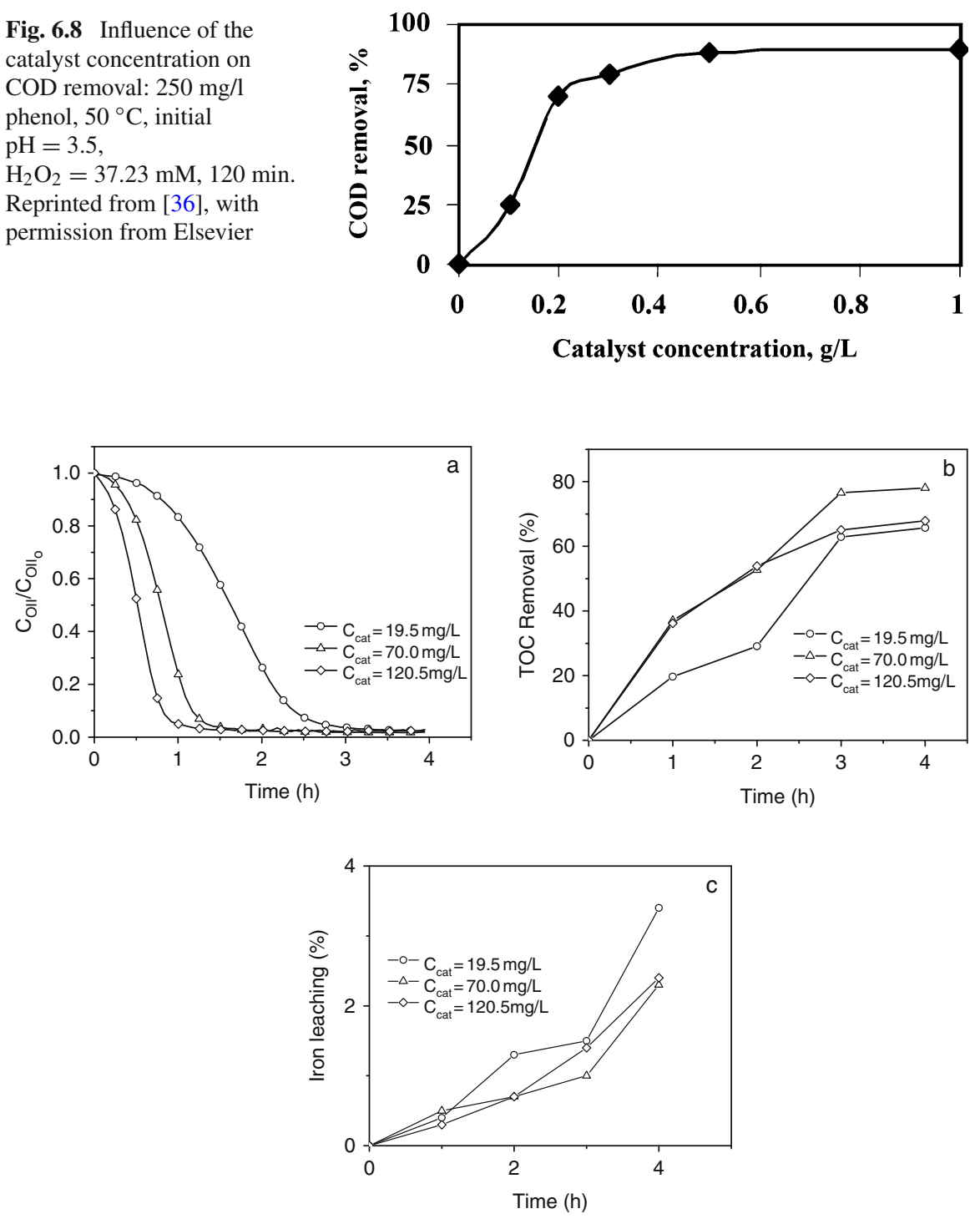

Fig. 6.9 Catalyst concentration effect on Orange II dye degradation (a), mineralization (b), and iron loss (c); $T=40{ }^{\circ} \mathrm{C}, \mathrm{C}_{\mathrm{H}_{2} \mathrm{O}_{2}}=1.3 \times 10^{-2} \mathrm{M}, \mathrm{pH}=3$. Reprinted from [26] with permission from American Chemical Society

The effect of the catalyst concentration on the non-biodegradable azo-dye Orange II degradation histories is shown in Fig. 6.9 [26]. It can be seen that the catalyst load affects positively the dye degradation rate, as expected, because more radicals are produced, thus leading to a faster color removal. In terms of TOC removal, $70 \mathrm{mg} / \mathrm{l}$ of catalyst leads to better results as compared to catalyst loads of 19.5 
and $120.5 \mathrm{mg} / \mathrm{l}$, which provide similar TOC removals after 3 or $4 \mathrm{~h}$ of oxidation. This indicates, as above-mentioned, that after a certain point the catalyst load has a detrimental effect on the performance (mineralization degree in this case), which can be explained by the formation of iron complexes (iron + organics) when excess amounts of catalyst are present [26]. Other authors have also found this kind of behavior with heterogeneous systems $[56,57]$. The scavenging of hydroxyl radicals (Eqs. 6.4-6.6) might also explain this effect [44], although other undesirable reactions between iron and other radicals could also be mentioned $[1,44,58]$ :

$$
\mathrm{FeOH}^{+}+\mathrm{HO}^{\bullet} \rightarrow \mathrm{Fe}^{3+}+2 \mathrm{OH}^{-}
$$

Finally, in terms of percentage of iron lost from the solid, referred to the total Fe initially incorporated, Fig. 6.9c shows that the differences are small, i.e., the percentage of iron that has been leached out depends only slightly on the catalyst concentration employed in the catalytic runs. It seems, however, that higher percentages of $\mathrm{Fe}$ are lost from the clay support when smaller catalyst doses are used.

Other authors [30], found a similar behavior using Fe-pillared montmorillonite for cinnamic acid removal. The authors observed that the maximum removal (90\%) of cinnamic acid after $1 \mathrm{~h}$ was obtained for the Fe/cinnamic acid molar ratio $=2$ in heterogeneous medium. Beyond this ratio the degradation rate did not increase (Fig. 6.10). In the homogenous medium, it was observed that the elimination of cinnamic acid was increased by increasing the Fe/cinnamic acid ratio up to a value of 10 , beyond which it became constant. In addition, it is worth noting that at all ratios of $\mathrm{Fe} / \mathrm{cinnamic}$ acid the removal of cinnamic acid was lower in the homogeneous medium than in the heterogeneous medium. This behavior was explained by an

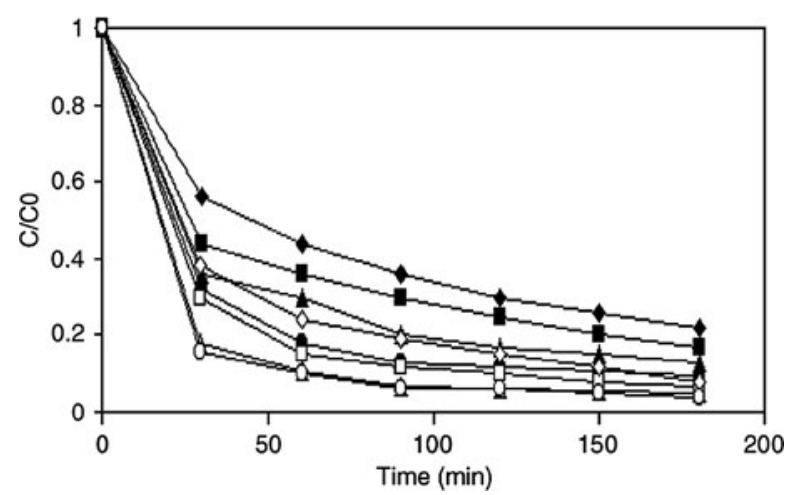

Fig. 6.10 The effect of Fe/cinnamic acid molar ratio on cinnamic acid removal as a function of time at $\mathrm{pH}=2.9$ and $\mathrm{H}_{2} \mathrm{O}_{2}$ /cinnamic acid molar ratio $=83$. Solid symbols refer to homogeneous catalysis and open symbols to heterogeneous catalysts: $(\diamond) \mathrm{Fe} /$ cinnamic acid molar ratio $=0.2,(\square)$ $\mathrm{Fe} /$ cinnamic acid molar ratio $=0.5,(\Delta) \mathrm{Fe} /$ cinnamic acid molar ratio $=2$, and (o) Fe/cinnamic acid molar ratio $=10$. Reprinted from [30], with permission from Elsevier 
easier complexation with the Fe ions in the homogeneous medium by organic intermediate degradation products, such as carboxylic acids, which can in turn diminish the removal rate of cinnamic acid [30].

\subsubsection{Effect of the Initial Parent Compound Concentration}

Several researchers have investigated the effect of the initial concentration of phenol in solution on the degradation performance. For example, Guo and Al-Dahhan [35], reported catalytic wet oxidation of phenol by $\mathrm{H}_{2} \mathrm{O}_{2}$ using a pillared clay catalyst. Figure 6.11 shows the conversion with time at four initial phenol concentrations, which demonstrate that a higher initial concentration leads to lower conversion under otherwise identical conditions. The same self-inhibiting effect of the phenol initial concentration on the oxidation rate was observed by Pintar and Levec [59]. The negative effect of the increasing parent organic compound/ $\mathrm{H}_{2} \mathrm{O}_{2}$ ratio on the cinnamic acid conversion was also reported by Tabet et al. [30].

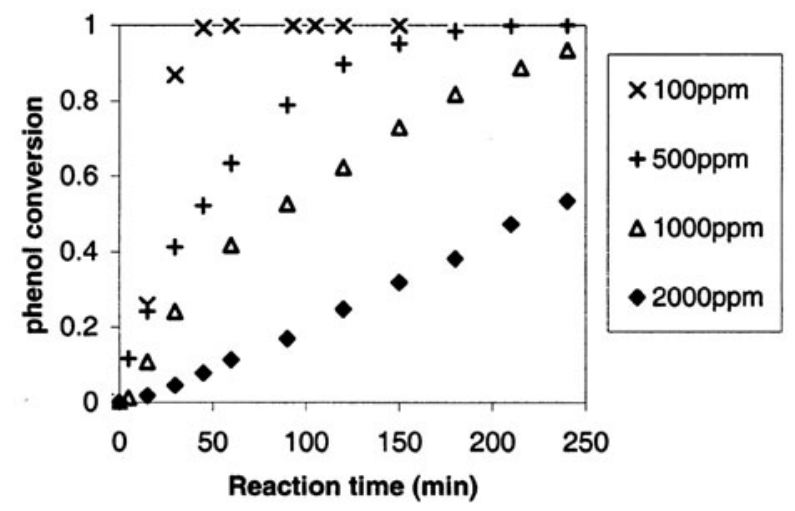

Fig. 6.11 Effect of initial phenol concentration on its reduction by catalytic wet oxidation $\left(70{ }^{\circ} \mathrm{C}\right.$, $0.3 \mathrm{M} \mathrm{H}_{2} \mathrm{O}_{2}, 6.6 \mathrm{~g} / \mathrm{l}$ catalyst). Reprinted from [35], with permission from American Chemical Society

\subsubsection{Heterogeneous Versus Homogenous Process}

The heterogeneous process has several advantages, as compared to the homogeneous one, as remarked by Tabet et al. [30]:

- It avoids the release of ferric cations into the discharged water;

- It might lead to higher removal rates of the parent compound (e.g., for cinnamic acid, by a factor of 1.5-2.5, depending on the operating conditions - cf. Figs. 6.3 and 6.10);

- It is often less sensitive to $\mathrm{pH}$ variations, in line with other reports, particularly in what concerns phenol and carboxylic acids degradation [31, 60]. 
The results obtained by Barrault et al. [34] also show that the TOC abatement obtained with the so-called FAZA catalyst, for phenol mineralization, is much higher than those observed with homogeneous iron species in the same reaction conditions. These results demonstrate unambiguously that the phenol oxidation reaction is due to the presence of a solid catalyst, the possible contribution of the homogeneous iron species arising from the catalyst leaching being likely negligible.

However, it is not very common to find reported higher activities for the heterogeneous system; actually, in most cases the opposite is observed. For instance, Tatibouët et al. [32] noticed that the phenol conversion level obtained after $2 \mathrm{~h}$ of reaction at $\mathrm{pH}=3.0-3.5$ is higher for the homogeneous reaction than for the catalytic heterogeneous one (using a PILC-like catalyst), although the iron content in the reactor for the heterogeneous system was more than 30 times higher than for the homogeneous one ( $>15 \mathrm{mg}$ for the heterogeneous system against $0.5 \mathrm{mg}$ for the homogeneous one - data not shown). This seems to be due to the induction period observed when a heterogeneous catalyst is used (Fig. 6.12), wherein catalytic performances of the same order of magnitude are reached with completely different catalyst doses (more than 30 times higher in the heterogeneous one, because one has to take into account the Fe content in the PILC sample: $2.0 \mathrm{wt} \%$ ). On the other hand, the same authors reported that the homogeneous system seems to be very sensitive to $\mathrm{pH}$ values higher than 3.0, leading to a dramatic decrease in the conversion level, from $>>80 \%$ at $\mathrm{pH}=3.0$ to less than $5 \%$ at $\mathrm{pH}=2.5$, whereas the

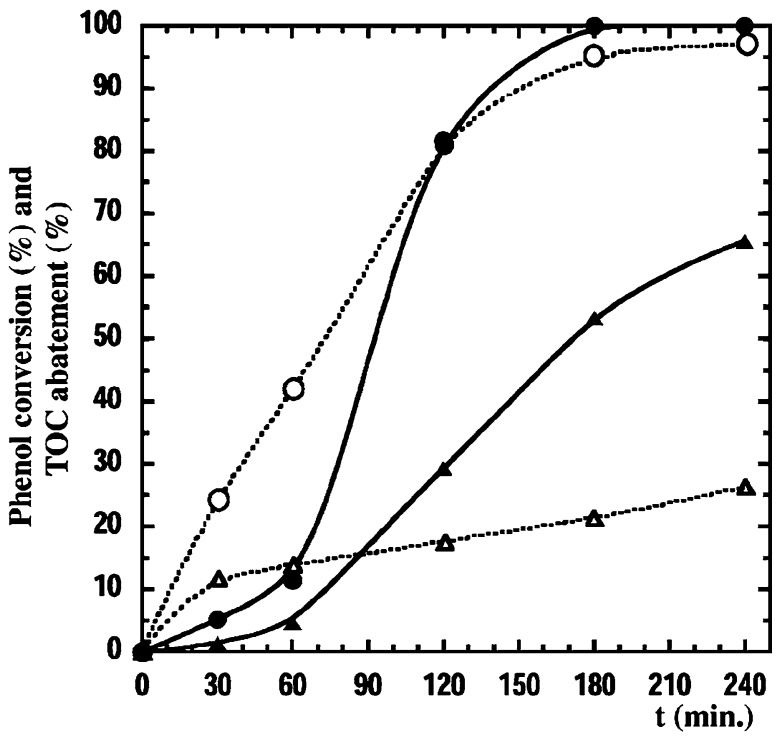

Fig. 6.12 Phenol oxidation by hydrogen peroxide (batch reactor, $T=25{ }^{\circ} \mathrm{C}$, $\left.\mathrm{H}_{2} \mathrm{O}_{2}=2 \times 10^{-4} \mathrm{~mol} / \mathrm{h}, \mathrm{pH}=3.7\right)$. Dotted lines and open symbols: homogeneous system $(\mathrm{Fe}=5 \mathrm{mg} / \mathrm{l})$, continuous line and solid symbols: FAZA catalyst $=5 \mathrm{~g} / \mathrm{l}$. ( $\bullet)$ Phenol conversion,

(ム) TOC abatement. With kind permission from Springer [32] 
heterogeneous system shows only a slight decrease in the phenol conversion from 25 to $17 \%$ in the same $\mathrm{pH}$ range [32]. The heterogeneous catalytic system appears then to be less sensitive to the $\mathrm{pH}$ value than the homogeneous one, in line with the afore-mentioned advantages pointed by Tabet et al. [30].

The measurement of HO. species production by an ESR spin trapping technique showed that the $\mathrm{HO}$. production followed the same profile in function of the $\mathrm{pH}$ value as the catalytic activity in phenol oxidation. This fact strongly suggests that the main active species are hydroxyl (HO-) and/or hydroperoxyl $\left(\mathrm{HO}_{2} \cdot\right)$ radicals generated by hydrogen peroxide reaction with iron species in homogeneous phase (Fenton reaction) or with iron surface species probably located in the clay porosity [32]. Then, Tatibouët et al. [32] conclude that the difference between homogeneous and heterogeneous systems could be due either to the formation of different active oxygen species from hydrogen peroxide or to the ability of the heterogeneous catalyst to adsorb on its surface the phenol and/or the reaction intermediate products, favoring their reaction with oxygen species formed by hydrogen peroxide activation. This phenomenon could be largely enhanced by the particular structure of the pillared clay where, in addition to the adsorbing properties of the pillared clay, the intermediate products of phenol oxidation could be trapped between the clay layers, favoring then their attack by the oxygenated radicals $\mathrm{HO}$. and $\mathrm{HO}_{2}$.

\subsubsection{Effect of the Type of Catalyst/Salt Precursor}

Ramirez et al. [25] studied the Fenton-like oxidation of Orange II solution using different heterogeneous catalysts based on saponite clay. The results obtained for the oxidation of OII solution with the 12 catalysts prepared are displayed in Fig. 6.13. Therein, the effect of the nature of the Fe-salt precursor as well as the amount of active phase used on the catalytic activity can be observed. For the catalyst with lowest $(7.5 \mathrm{wt} \%)$ and highest $(17.0 \mathrm{wt} \%)$ iron contents, the best results were always reached when using the oxalate precursor (Fig. 6.13a and c, respectively), while for the catalysts containing the intermediate concentration (13.0 $\mathrm{wt} \%)$, the best sample seems to be that prepared with the acetate precursor (Fig. 6.13b). Using the clay impregnated with $13.0 \%$ of $\mathrm{Fe}(\mathrm{II})$ acetate and $17.0 \%$ of $\mathrm{Fe}(\mathrm{II})$ oxalate, degradations of 95.2 and $95.9 \%$ were obtained after $4 \mathrm{~h}$, respectively.

It can also be observed in Fig. 6.13 that the influence of the iron concentration on the degradation of Orange II is not equal for all the precursors, but, in general, the final performances are not too different. The reason behind this fact is not clear, and a deeper insight regarding the mechanisms occurring in the system is required. Nevertheless, TOC elimination shows clearly that at the end of the runs it increases, for each precursor, with the iron load [25]. This increment in the mineralization with the iron concentration occurs because when the amount (concentration) of catalyst increases, more radicals are produced for the oxidation reaction (Eqs. 6.11 and 6.12, where $X$ represents the surface of the catalyst): 

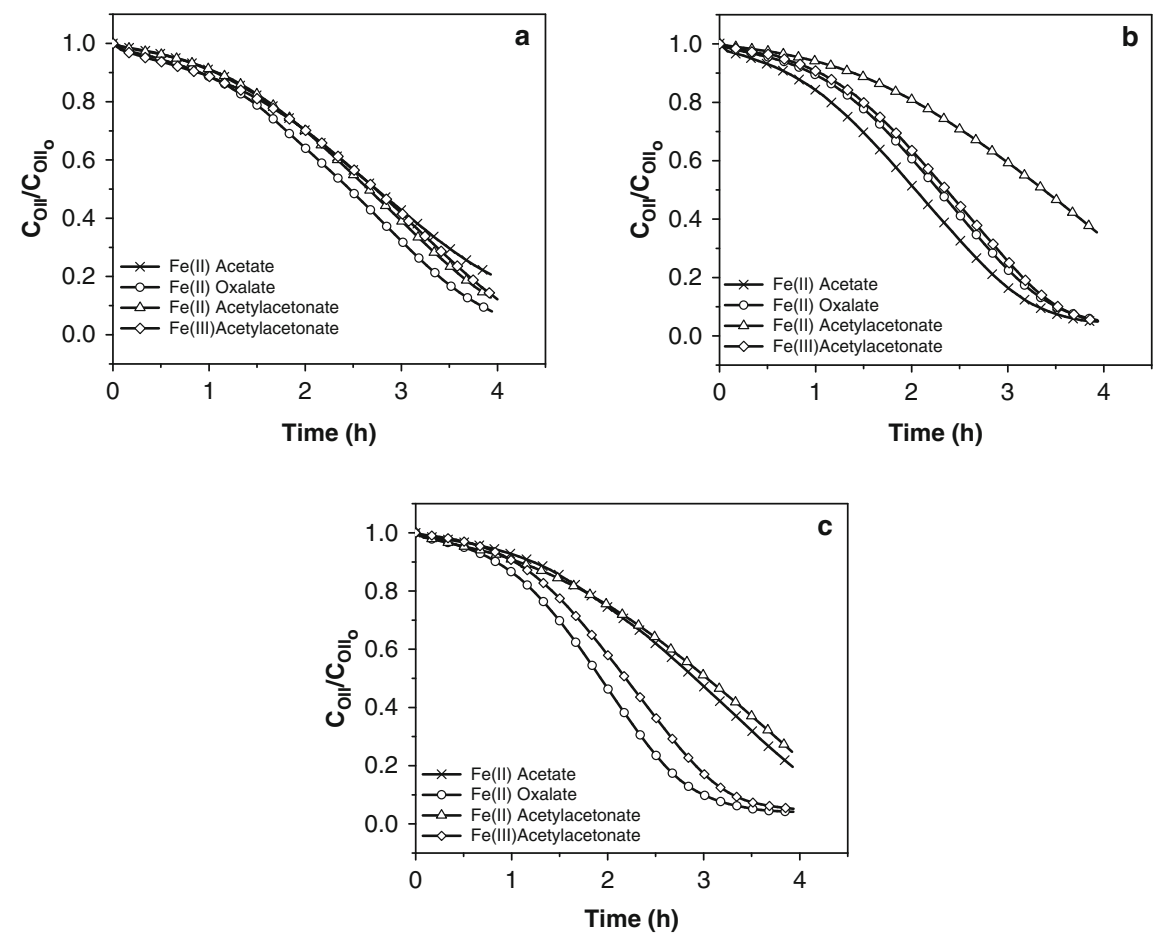

Fig. 6.13 Effect of the precursor nature on the degradation of the OII solution for different iron loads:. (a) $7.5 \mathrm{wt} \%$, (b) $13.0 \mathrm{wt} \%$, (c) $17.0 \mathrm{wt} \%, \mathrm{pH}=3, \mathrm{C}_{\mathrm{H}_{2} \mathrm{O}_{2}}=6 \times 10^{-3} \mathrm{M}$, and $T=30^{\circ} \mathrm{C}$. Reprinted from [25], with permission from Elsevier

$$
\begin{gathered}
\mathrm{X}-\mathrm{Fe}^{3+}+\mathrm{H}_{2} \mathrm{O}_{2} \rightarrow \mathrm{X}-\mathrm{Fe}^{2+}+\mathrm{HO}_{2}^{\bullet}+\mathrm{H}^{+} \\
\mathrm{X}-\mathrm{Fe}^{2+}+\mathrm{H}_{2} \mathrm{O}_{2} \rightarrow \mathrm{X}-\mathrm{Fe}^{3+}+\mathrm{OH}^{-}+\mathrm{HO}^{\bullet}
\end{gathered}
$$

The catalytic differences observed when different precursors are used are not clear. Nevertheless, several factors might be indicated, which are known to affect the catalytic performance: (i) the iron dispersion [1], (ii) the $\mathrm{Fe}_{2} \mathrm{O}_{3}$ crystalline form (hematite or maghemite-Q) [16], (iii) the location of the iron species (bonded to the aluminum pillars or engaged in small oxide clusters dispersed in the solid, inside, or outside the porosity) [34], or (iv) the oxidation states, nature, and coordination of the iron species [38].

Other authors, for example Chirchi and Ghorbel [37], carried out a study about degradation of 4-nitrophenol using various Fe-modified montmorillonite catalysts. They tested 11 different catalysts, prepared under different conditions (namely, $\mathrm{pH}$ ) and experimental procedures and found that the best results were obtained with PILC-(Al-Fe), a pillared sample constituted by pillars of mixed $\mathrm{Al}$ and Fe oxides, which was selected to be the best catalyst for the heterogeneous degradation of 4-nitrophenol. 


\subsubsection{Some Technological Issues}

Although some technical issues that are quite important to take into account for industrial implementation of a heterogeneous Fenton-like process have already been discussed, others need to be analyzed in detail. This will be the main focus of the following sections.

\subsubsection{Catalyst Stability}

For a practical implementation of a heterogeneous catalytic system, it is crucial to evaluate the stability of the catalysts. Ideally, a sample that shows a low leaching, but presenting simultaneously good catalytic performance, should be selected. In the case of a Fenton process, iron leaching should ideally be null to provide longterm stability. This is particularly interesting from the practical point of view due to the possibility of using these catalysts for a longer operation time/larger number of cycles (batch mode).

In this concern, Luo et al. [53] investigated the iron leaching from the support into the solution, for a catalytic Fenton's process using Al-Fe-pillared clay in phenol oxidation. They found that the loss of iron amounted to $0.1 \mathrm{mg}$, equivalently $0.3 \%$ of total iron of $0.3 \mathrm{~g}$ catalyst used. With such a low level of iron in the solution, they concluded that the homogeneous Fenton reaction is negligible. Compared to a dissolved iron concentration of $2.0 \mathrm{mg}^{-1}$ obtained at $\mathrm{pH} 3.0-3.5$ and $1.0-2.0 \mathrm{mg} \mathrm{l}^{-1}$ at $\mathrm{pH} \mathrm{3.0,} \mathrm{the} \mathrm{much} \mathrm{lower} \mathrm{iron} \mathrm{loss} \mathrm{in} \mathrm{this} \mathrm{work} \mathrm{was} \mathrm{attributed}$ to the less acidic conditions ( $\mathrm{pH} 3.5-4.7)$. Then, they studied the re-use of $\mathrm{Fe}-\mathrm{Al}$ powder catalyst, employing two procedures to recycle the powder catalyst:

(a) Centrifugal separation of the used powder and washing with plenty of water. The slurry was used for further catalysis, and alternatively

(b) The washed slurry from procedure (a) was dried at $80^{\circ} \mathrm{C}$ in an oven for $5 \mathrm{~h}$. The dried powder was also used as a catalyst.

Both of the recycled catalysts were used more than three times with no obvious deactivation as shown in Fig. 6.14. However, the induction times for the re-used powder varied depending on the procedure of recovery. The induction time from procedure (a) decreased (samples denoted as "S" - slurry, in the figure), while from procedure (b) (samples denoted as "P" - powder, in the figure) it remained almost the same as with the original powder. This is probably because the slurry from procedure (a) kept the protonated surface iron species, while the dried powder from procedure (b) lost them, thus requiring a further induction period to allow them to regenerate [53].

Catrinescu et al. [36] studied a similar process, phenol degradation, but using Fe-exchanged pillared beidellite-like catalyst. They re-used the material in three consecutive experiments, with the same catalyst load at $\mathrm{pH} 3.5$ and $30{ }^{\circ} \mathrm{C}$. Between each experiment the catalyst was removed by filtration, followed by drying at $80{ }^{\circ} \mathrm{C}$ for $12 \mathrm{~h}$. The results are reported in Fig. 6.15. It is obvious that the initial activity 


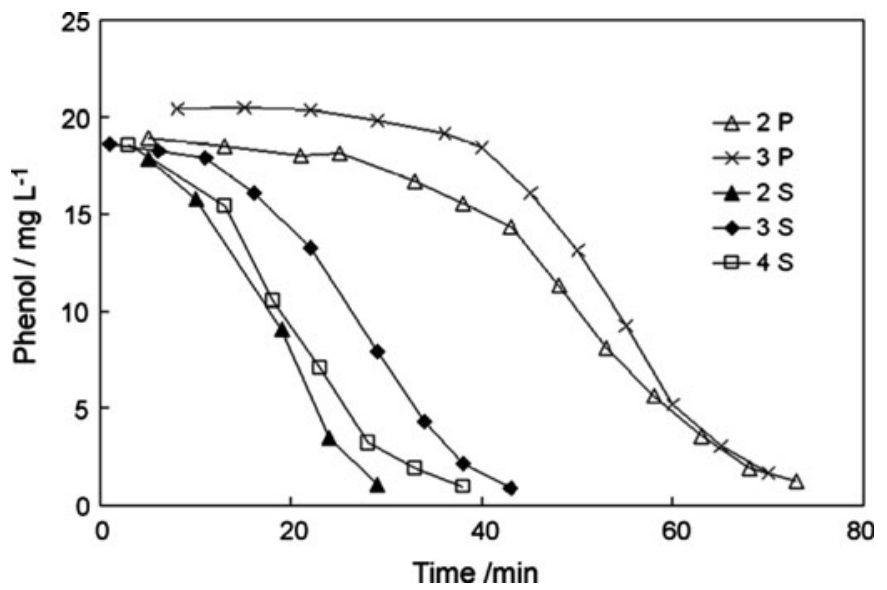

Fig. 6.14 Re-use of catalyst in the form of either a powder slurry or a dried powder. The numbers indicated the repeated use of the catalyst, i.e., 2 means the material was used for second time. The letters refer to re-use as dried power (P) or slurry (S). Reprinted from [53], with permission from Elsevier

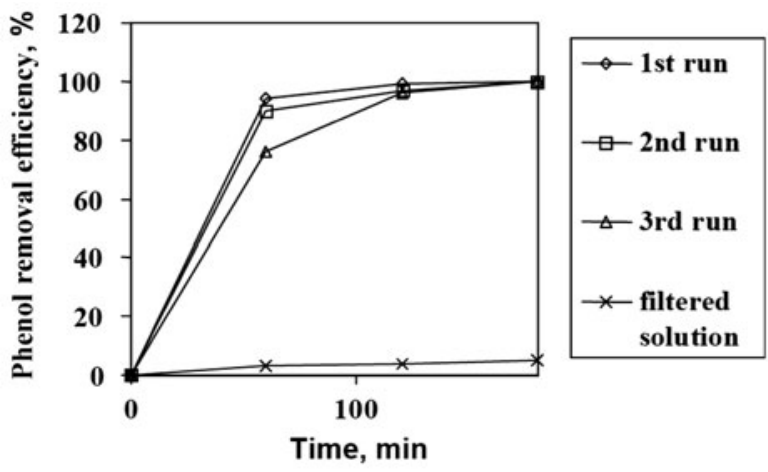

Fig. 6.15 Conversion of phenol as function of the time of reaction in different conditions: fresh catalyst, re-used once, re-used twice, after the filtration of the catalyst and the addition of phenol and $\mathrm{H}_{2} \mathrm{O}_{2} ; 250 \mathrm{ppm}$ phenol, $50{ }^{\circ} \mathrm{C}, 0.5 \mathrm{~g} / \mathrm{l}$ PILC catalyst; $37.23 \mathrm{mM} \mathrm{H}_{2} \mathrm{O}_{2}$; initial $\mathrm{pH}=3.5$. Reprinted from [36], with permission from Elsevier

decreased slowly during successive runs. However, at longer times, phenol removal is comparable for all the experiments. The poisoning of the active catalytic sites was considered by the authors as the reason for this initial loss of activity. The oxidation of the organic species adsorbed on the catalyst active sites may be associated with the delays observed for short reaction times. When the catalyst was used after an intermediate calcination step, its catalytic activity was restored, indicating the absence of significant deactivation, due to the loss of iron. Moreover, in the absence 
of solid catalyst (after filtration) the catalytic activity is negligible, clearly demonstrating that the fraction of iron leached from the catalyst is not capable of destroying the organic pollutant [36].

Fig. 6.16 Effect of consecutive experiments with the Fe(II) oxalate 17.0 catalyst on the degradation of OII solution. $\mathrm{pH}=3$, $T=30^{\circ} \mathrm{C}$, $\mathrm{C}_{\mathrm{H}_{2} \mathrm{O}_{2}}=6 \times 10^{-3} \mathrm{M}$. Reprinted from [25], with permission from Elsevier

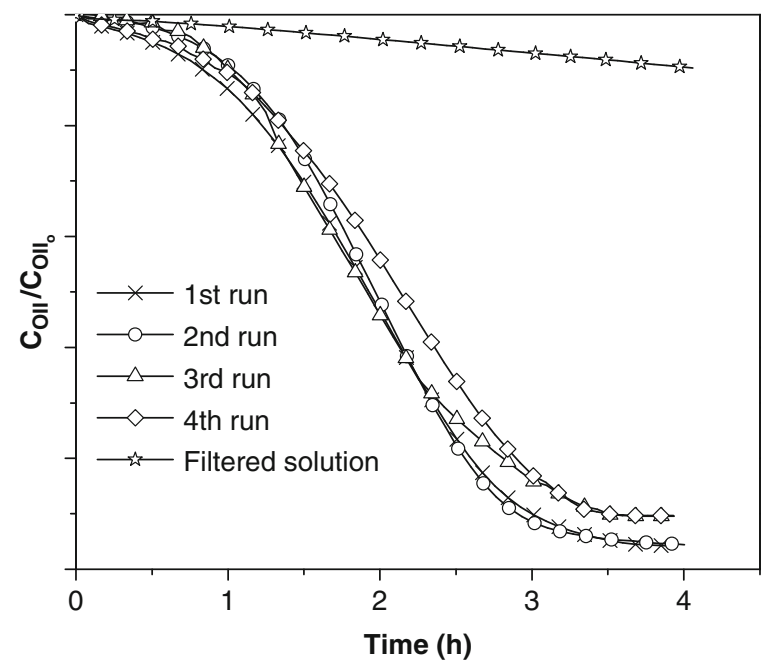

Similar conclusions were reached in a recent study, illustrated in Fig. 6.16, which shows the performance reached in terms of OII degradation, using a clay-based catalyst in four consecutive runs [25]. To recover the catalyst, the final effluent was filtered. After the first cycle, and in order to check if the leached iron was responsible for the catalytic activity, both $\mathrm{OII}$ and $\mathrm{H}_{2} \mathrm{O}_{2}$ were added to the solution in the same concentrations as at the beginning of the experiment. Figure 6.16 shows that in these conditions OII conversion is only a very small fraction of that recorded in the presence of the pillared clay, thus demonstrating that the Fe leached is not capable of destroying the dye, i.e., the process is essentially heterogeneous. For subsequent cycles, the filtered clay was dried overnight between consecutive runs. Even though a slight activity decay is observed, which might be due to the iron loss (ca. 1.5\% per cycle that represents a final concentration smaller than $0.3 \mathrm{mg} / \mathrm{l})$, OII conversion decreases only from 95.8 to $90.3 \%$ in 4 cycles, i.e., 16 h of operation. Regarding TOC reduction, in the 4 cycles final values were $81.6,81.4,78.5$, and $77.1 \%$. In practice, this small deactivation could be compensated, if required, by adapting the reaction conditions (for instance, slightly increasing the temperature along time). As already mentioned, other authors reported similar results, but they attributed the loss of activity to poisoning of the active catalytic sites due to adsorbed organic species $[1,36]$. However, this could be avoided by submitting the catalyst to an intermediate calcination step, thus restoring its catalytic activity [31, 36]. Nevertheless, catalyst deactivation may occur due to a diversity of factors, as pointed by Guo and Al-Dahhan [35], including reduction of the catalyst specific surface area, poisoning of the catalytic agents by compounds formed during oxidation, surface deposition, 
and strong adsorption of a polymeric carbon layer or even the dissolution of some metal oxides from catalysts into the hot acidic reaction medium. This issue should therefore be the aim of more intensive research and future work.

Other studies addressed this matter of catalyst re-use, e.g., see Refs. [34, 35], pointing very often to good stability. However, in most cases the number of cycles has been very limited, usually not exceeding ca. 4, thus not allowing true long-term catalytic activity evaluation. Other methodologies are required, for instance, testing in continuous reactors for much longer times.

\subsubsection{Use of Continuous Flow Reactors}

Operation with continuous reactors is desirable for real practice, but the studies reported in the literature are limited, as compared to those employing batch reactors. One scarce example is provided in the work by Tatibouët et al. [32], whom have studied the catalytic oxidation of phenol by hydrogen peroxide over a pillared clay containing iron in a continuous flow reactor. Such reactor allowed the determination of the kinetic parameters of the reaction in steady-state conditions. In this work the authors assumed first-order kinetics for the phenol conversion rate, and thus the mass balance in a perfectly stirred reactor yields:

$$
X=\frac{k \tau}{1+k \tau}
$$

with:

$$
\begin{aligned}
& X=\text { phenol conversion } \\
& k=\text { rate constant }\left(\mathrm{ml} \mathrm{min}{ }^{-1} \mathrm{~g}^{-1}\right) \\
& \tau=\text { catalyst weight/total flow rate }\left(\mathrm{g} \mathrm{min} \mathrm{ml}^{-1}\right)
\end{aligned}
$$

From the above equation, one obtains

$$
\frac{1}{X}=1+\frac{1}{k \tau}
$$

The rate constant $k$ is then determined as the slope of the straight line obtained by drawing $1 / X$ as a function of $1 / \tau$. The best fit was obtained for a constant $k$ value equal to $0.18 \mathrm{ml} \mathrm{min}^{-1} \mathrm{~g}^{-1}$, which was used to draw the calculated phenol conversion curve (dotted line) of Fig. 6.17, showing that their simple kinetic model fits very well with the experimental results, especially for a conversion lower than $70 \%$.

Another study about oxidation of phenol, over pillared clays containing iron in a continuous flow reactor [33], was carried out by the same group. They concluded that the high stability of this pillared clay catalyst in the reaction conditions employed and its good catalytic performance in TOC abatement $\left(\approx 80 \%\right.$ at $\left.70{ }^{\circ} \mathrm{C}\right)$ would allow them to use it in a continuous process, being able to eliminate organic pollutants in industrial wastewater streams. 
Fig. 6.17 Variation of the phenol conversion as a function of residence time in the recycling continuous flow reactor $\left(T=40^{\circ} \mathrm{C}\right.$,

$C_{\text {phenol }}=5 \times 10^{-4} \mathrm{M}$,

$\left.\mathrm{C}_{\mathrm{H}_{2} \mathrm{O}_{2}}=0.01 \mathrm{M}\right)$. Dotted

line: simulation for

$k=0.18 \mathrm{ml} \mathrm{min}^{-1} \mathrm{~g}^{-1}$ in Eq.

6.13. With kind permission from Springer, figure 5 [32]

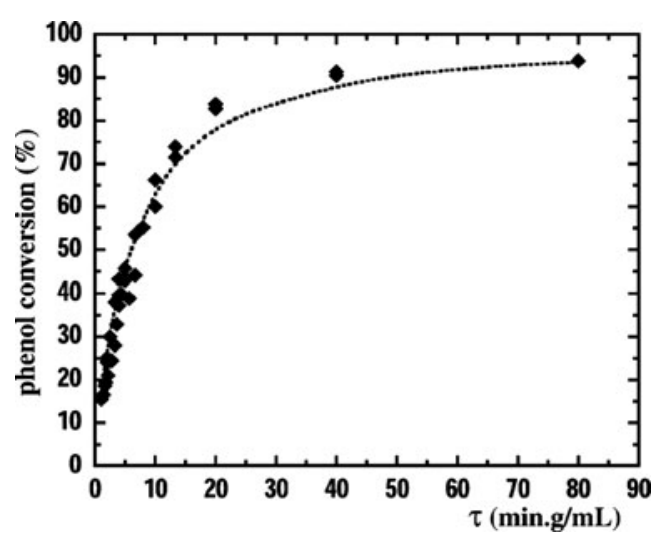

\subsubsection{Mechanistic Studies}

Up to our knowledge, there are not many studies reporting the identification/quantification of intermediates and establishing reaction mechanisms during Fenton-like processes based on PILCs. A scarce example has been reported by Guo and Al-Dahhan [35], whom identified the intermediate products of phenol oxidation by hydrogen peroxide. The main detected intermediates in the product effluent were acetic acid, catechol, and hydroquinone. Oxalic acid and benzoquinone were also identified in measurable quantities. However, malonic and formic acids were detected only as traces. No other compounds were detected in measurable amounts. In particular, no condensation products were found in the exiting solution or deposited on the catalysts. Quinone-like products such as hydroquinone, benzoquinone, and catechol were identified in the first stages of the phenol oxidation pathway [35]. These by-products need, however, to be removed because they are as toxic as phenol.

Based on the HPLC analyses and the evolution of the color along time (related with the presence of benzoquinone), a simplified reaction scheme was proposed, shown in Fig. 6.18, where the important interconnection between the presence of quinones and organic acids can be seen. The first step represents the formation of intermediate ring compounds, namely, catechol, hydroquinone, and benzoquinones, whereas the subsequent stage corresponds to the cleavage of intermediates and the formation of carboxylic acids. This scheme is in line with the conclusion of Fortuny et al. [61], except that the possibility of direct decomposition of phenol to inorganic carbon during the ring-opening reaction is also taken into account by Guo and Al-Dahhan [35]. 
Fig. 6.18 Proposed reaction scheme for phenol oxidation. Reprinted from [35], with permission from American Chemical Society

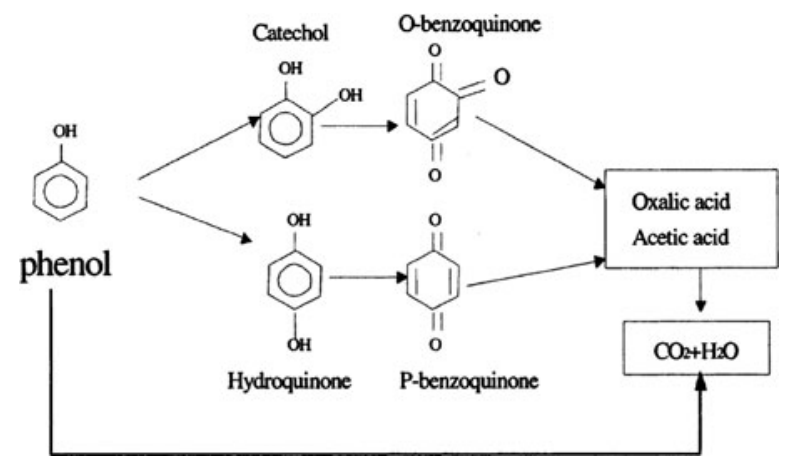

\subsection{Modeling}

Modeling is a crucial issue, for instance, in the design of industrial-scale reactors. For that, degradation rate equations are required, which can be obtained via kinetic studies and subsequent phenomenological modeling. Statistical models, which we will call as semi-empiric, have also been often used for modeling purposes, allowing predicting process response and providing a tool for process optimization. Both will be described in the following sections, given their importance and the fact that have been used in modeling Fenton-like processes employing PILCs.

\subsubsection{Phenomenological Models}

\subsubsection{Langmuir-Hinshelwood Rate Equations}

In the literature, different kinetic strategies can be found for the interpretation and modeling of Fenton and Fenton-like oxidation processes using PILCs, in particularly using well-known Langmuir-Hinshelwood ( $\mathrm{LH})$ formulations. Guo and Al-Dahhan [35], assuming that the homogeneous and heterogeneous reaction rates are additive, presented a network model which was suggested to account for the significant reaction both in the liquid bulk phase and on the catalytic surface of an Al-Fe-pillared clay during Fenton-like phenol conversion. They considered a two-parallel reaction scheme for the non-catalytic oxidation and a LangmuirHinshelwood approach for the catalyst-mediated oxidation. In this work on phenol oxidation with hydrogen peroxide as the oxidant, experimental evidence indicates that approximately $30-40 \%$ of hydrogen peroxide homogeneously decomposes in the liquid bulk, while the other portion decomposes in contact with the clay catalyst. In Guo and Al-Dahhan's study [35], the catalyst loading term in the heterogeneous reaction rate is modified in an empirical way by including the exponent terms for both the phenol removal and the intermediate products degradation. To preserve the units of the reaction rates, it has been shown that the exponent terms have to have 
the same value, $p$ (which was determined to be 0.798), as shown in the following equations:

$$
\begin{gathered}
-\frac{\mathrm{d} C_{\mathrm{A}}}{\mathrm{d} t}=r_{\mathrm{h}, \mathrm{A}}+r_{\mathrm{H}, \mathrm{A}} C_{\text {cat }}{ }^{p} \\
\frac{\mathrm{d} C_{\mathrm{B}}}{\mathrm{d} t}=r_{\mathrm{h}, \mathrm{B}}+r_{\mathrm{H}, \mathrm{B}} C_{\text {cat }} p
\end{gathered}
$$

where $r_{\mathrm{h}, \mathrm{A}}$ represented the development of the homogeneous kinetic model (with rate $r_{\mathrm{h}}$ ) using the homogeneous experimental data, and $r_{\mathrm{H}, \mathrm{A}}$ the development of the heterogeneous kinetic model (with rate $r_{\mathrm{H}}$ ) using the heterogeneous experimental data. In the latter, the homogeneous model with its fitted parameters needed also to be considered, due to leaching.

Because the reaction networks involved in wastewater treatment through AOPs are rather complex, several authors have adopted the methodology of lumped models. In this case, three basic lumps are considered in the reaction system, which are expressed in carbon concentration terms for oxidation kinetics: (1) phenol, denoted as A; (2) intermediate organic carbon, denoted as lump B, is the phenol oxidation by-product; and (3) total inorganic carbon, denoted as lump $\mathrm{C}$, is the fully mineralized end products. On the basis of the carbon scale, $C_{\mathrm{B}}=\mathrm{TOC}-C_{\mathrm{A}}$ and $C_{\mathrm{C}}=C_{\mathrm{Ao}}-\mathrm{TOC}$.

To model the homogeneous contribution, i.e., the non-catalytic oxidation route with rate $r_{\mathrm{h}}$, a sequential-parallel reaction scheme was proposed as in Eqs. (6.176.19), where the production of lump $\mathrm{C}$ is generated by irreversible oxidation of both A and lump B [35]. Lump B results from the irreversible oxidation of A. The homogeneous reactions are as follows:

$$
\begin{aligned}
& \mathrm{H}_{2} \mathrm{O}_{2}+\mathrm{A} \stackrel{k_{\mathrm{h}_{1}}}{\longrightarrow} \mathrm{B} \\
& \mathrm{H}_{2} \mathrm{O}_{2}+\mathrm{A} \stackrel{k_{\mathrm{h}_{2}}}{\longrightarrow} \mathrm{C} \\
& \mathrm{H}_{2} \mathrm{O}_{2}+\mathrm{B} \stackrel{k_{\mathrm{h}_{3}}}{\longrightarrow} \mathrm{C}
\end{aligned}
$$

The mass balances and reaction rates with respect to species $\mathrm{A}$ and $\mathrm{B}$ are given in the following equations:

$$
\begin{gathered}
-\frac{\mathrm{d} C_{\mathrm{A}}}{\mathrm{d} t}=r_{\mathrm{h}, \mathrm{A}}=\left(k_{\mathrm{h}_{1}}+k_{\mathrm{h}_{2}}\right) C_{\mathrm{A}} C_{\mathrm{H}_{2} \mathrm{O}_{2}} \\
\frac{\mathrm{d} C_{\mathrm{B}}}{\mathrm{d} t}=r_{\mathrm{h}, \mathrm{B}}=k_{\mathrm{h}_{1}} C_{\mathrm{A}} C_{\mathrm{H}_{2} \mathrm{O}_{2}}-k_{\mathrm{h}_{3}} C_{\mathrm{B}} C_{\mathrm{H}_{2} \mathrm{O}_{2}}
\end{gathered}
$$

In the presence of catalyst, both the heterogeneous and the homogeneous oxidation reactions take place at the same time. Once the homogeneous oxidation kinetic 
parameters are established and known, the parameters for the heterogeneous oxidation model are obtained by combining the heterogeneous experimental data with the fitted homogeneous reaction kinetic parameters, as explained above.

The heterogeneous elementary steps are characterized by adsorption of the reactants on the active sites of the catalyst (represented by ${ }^{*}$ ), followed by surface reaction and desorption of the products back into the liquid, which can be presented as follows [35]:

$$
\begin{gathered}
\mathrm{A}+* \stackrel{K_{\mathrm{HA}}}{\longrightarrow} \mathrm{A}^{*} \\
\mathrm{H}_{2} \mathrm{O}_{2}+\mathrm{A}^{*} \stackrel{k_{\mathrm{H}_{1}}}{\longrightarrow} \mathrm{B} * \\
\mathrm{H}_{2} \mathrm{O}_{2}+\mathrm{B}^{*} \stackrel{k_{\mathrm{h} 2}}{\longrightarrow} \mathrm{C}+{ }^{*} \\
\mathrm{~B}^{*} \stackrel{K_{\mathrm{HB}}}{\longleftrightarrow} \mathrm{B}+{ }^{*}
\end{gathered}
$$

In this model several assumptions are made, as explained by the authors [35]. Among them one can highlight that hydrogen peroxide is assumed to remain unadsorbed on the active sites, thus reacting directly with chemisorbed phenol. In addition, the steps of adsorption and desorption are assumed to be instantaneous as compared to surface reactions of chemisorbed phenol and its daughter intermediate products, which are the rate-controlling steps. The depletion rates of phenol and intermediate product due to the heterogeneous reaction can therefore be described by the following LH equations:

$$
\begin{gathered}
r_{\mathrm{HA}}=\frac{k_{\mathrm{H}_{1}} K_{\mathrm{HA}} C_{\mathrm{A}} C_{\mathrm{H}_{2} \mathrm{O}_{2}}}{1+K_{\mathrm{HA}} C_{\mathrm{A}}+K_{\mathrm{HB}} C_{\mathrm{B}}} \\
r_{\mathrm{HB}}=\frac{k_{\mathrm{H}_{1}} K_{\mathrm{HA}} C_{\mathrm{A}} C_{\mathrm{H}_{2} \mathrm{O}_{2}}}{1+K_{\mathrm{HA}} C_{\mathrm{A}}+K_{\mathrm{HB}} C_{\mathrm{B}}}-\frac{k_{\mathrm{H}_{2}} K_{\mathrm{HB}} C_{\mathrm{B}} C_{\mathrm{H}_{2} \mathrm{O}_{2}}}{1+K_{\mathrm{HA}} C_{\mathrm{A}}+K_{\mathrm{HB}} C_{\mathrm{B}}}
\end{gathered}
$$

where $K_{i}$ stands for adsorption equilibrium constant of species $i$.

Model parameters were obtained following the criteria described by Guo and Al-Dahhan [35]. The comparison between the model and the experimental results can be observed in the following figures, for either homogeneous or heterogeneous experiments. Reasonably good fits of the desired reactant (Fig. 6.19) and product compositions (data not shown for brevity) were achieved for the homogeneous reaction. The prediction results based on the catalytic reaction model also agree well with the experimental measurements of A and lump B obtained at temperatures from 30 to $90^{\circ} \mathrm{C}$, as shown in Figs. 6.20 and 6.21. Consequently, the homogeneousheterogeneous approach demonstrated to be a feasible and useful tool in the kinetic analysis for such complex reaction systems.

Compared to the non-catalytic route, the catalytic one should reduce the activation energies or increase the pre-exponential factors. The activation energies 
Fig.6.19 Measured and predicted time profiles for phenol removal in the homogeneous reaction at different temperature (500 ppm phenol, 0.3 M $\mathrm{H}_{2} \mathrm{O}_{2}$ ). Reprinted from [35], with permission from American Chemical Society
Fig. 6.20 Measured and predicted time profiles of phenol removal at different temperatures $(6.6 \mathrm{~g} / \mathrm{l}$ catalyst, $500 \mathrm{ppm}$ phenol, $0.3 \mathrm{M}$ $\mathrm{H}_{2} \mathrm{O}_{2}$ ). Reprinted from [35], with permission from American Chemical Society
Fig. 6.21 Parity plot for lump B concentration $\left(\mathrm{mol} / \mathrm{m}^{3}\right)$ in the heterogeneous reaction. Reprinted from [35], with permission from American Chemical Society
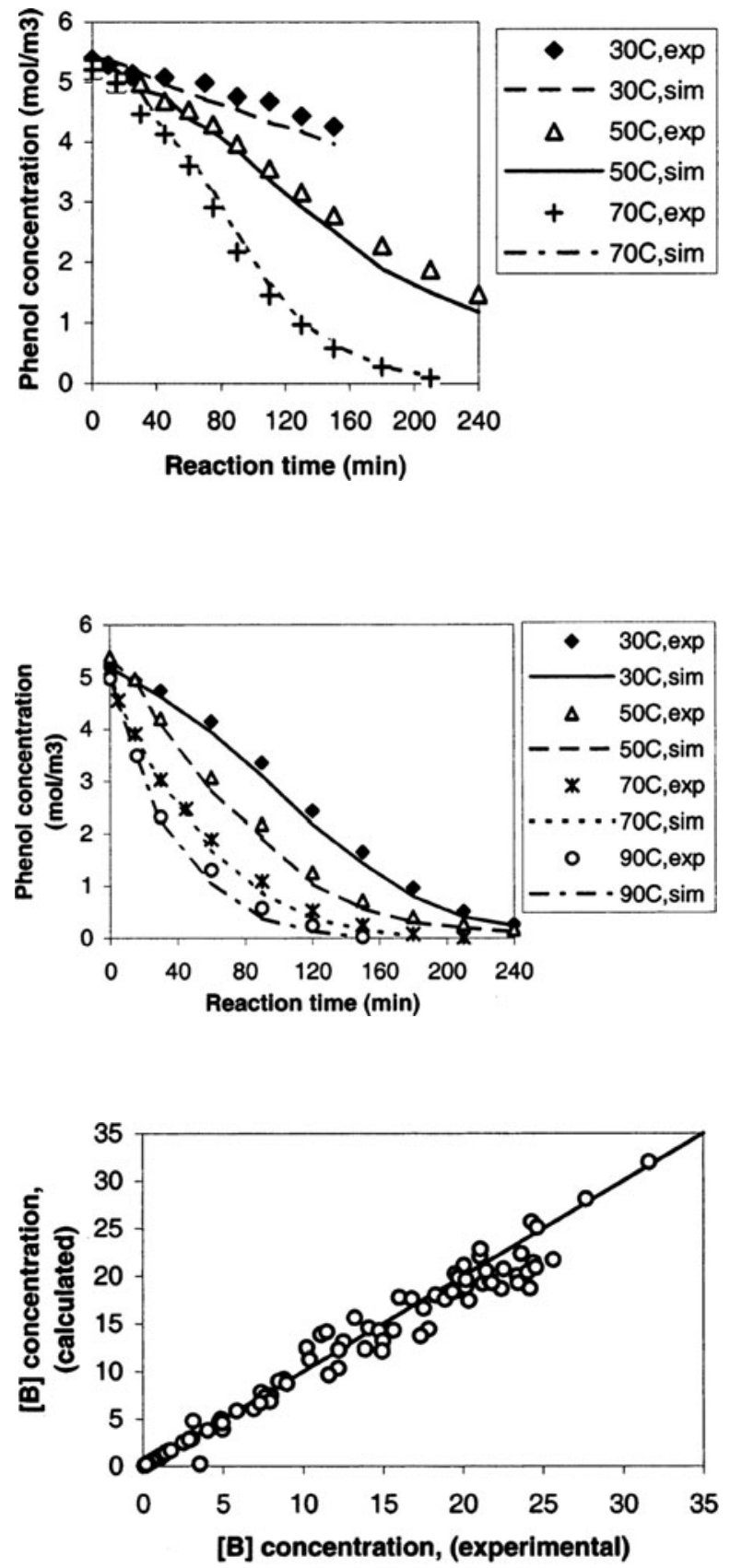
obtained for the degradation of phenol into intermediate products and the mineralization of the latter were 6.447 and $8.437 \mathrm{~kJ} / \mathrm{mol}$ in heterogeneous reaction and the counterparts in homogeneous reaction were 13.157 and $44.596 \mathrm{~kJ} / \mathrm{mol}$, respectively [35]. In addition, the high value of the activation energy for the mineralization of intermediate products without catalyst demonstrates their recalcitrance nature.

\subsubsection{Apparent First-Order Rate Equations}

Most often, apparent rate equations have been adopted, usually of the first-order type. Actually, these equations are not really phenomenological, but since they are not obtained via statistic methods, we decided to include them in this section. We call them apparent because several processes can contribute to the overall conversion of the parent compound, even though the extent of each one might be quite different. For example, the following steps can occur simultaneously: adsorption on the catalyst and oxidation by radicals (hydroxyl and others) coming from the heterogeneous or homogeneous process.

One example is the Fenton-like 4-nitrophenol (NP) degradation by $\mathrm{H}_{2} \mathrm{O}_{2}$ reported by Chirchi and Ghorbel [37], who have used a Fe-modified montmorillonite catalyst. The authors found a first-order model to be useful to fit the experimental values (considering thus a steady-state $\mathrm{OH}$ radical concentration during the degradation). In addition, the kinetic plot for the degradation of NP as a function of the concentration of $\mathrm{H}_{2} \mathrm{O}_{2}$ showed a reaction order of 0.5 , suggesting in their opinion that dissociation of $\mathrm{H}_{2} \mathrm{O}_{2}$ into two radicals ( $\mathrm{HO}$ ), probably on the surface of the catalyst, could be the rate-determining step. The reaction rate for the degradation was thus as follows:

$$
-\frac{\mathrm{d} C_{\mathrm{NP}}}{\mathrm{d} t}=k C_{\mathrm{NP}} C_{\mathrm{H}_{2} \mathrm{O}_{2}} 0.5
$$

\subsubsection{Non-Phenomenological Models}

As mentioned before, statistical models have been often used for modeling purposes, allowing predicting process response and providing a tool for process optimization. This has been achieved, for instance, using design of experiments (DoE) approaches and also neural networks.

In the case of Fenton-like processes this is particularly important because several independent variables affect process performance, as described along this chapter. Thus, process optimization is not straightforward. Although many researchers have usually only focused on the single-factor-at-a-time approach, studying the effect of each experimental parameter on the process performance while keeping all other conditions constant, this approach does not take into account the cross-effects from the factors considered, is time-consuming and leads to a poor optimization result. When a multifactor system is present, it is more appropriate to employ statistically 
based optimization strategies to achieve such a goal, with a minimum number of experiments. An example of using such methodology is provided in a paper by our group. Therein, Ramirez et al. [26] developed semi-empirical models with the goal of predicting and then maximizing color and total organic carbon removal, while minimizing the iron loss from the support during Orange II degradation using a clay-based Fenton-like catalyst.

First, models for each response $(Y)$ have to be developed, by fitting second-order equations of the type:

$$
Y=a_{0}+\sum_{j=1}^{n} a_{j} X_{j}+\sum_{j=1}^{n} a_{j j} X_{j}^{2}+\sum_{i>j}^{n} \sum_{j=1}^{n} a_{j i} X_{j} X_{i}
$$

to the experimental data. In Eq. (6.29), the independent variables $\left(X_{i}\right)$ considered were the temperature, $\mathrm{H}_{2} \mathrm{O}_{2}$ concentration, and catalyst load. The terms $a_{i}$ were determined by least squares analysis. In most cases, all the cross-effects and
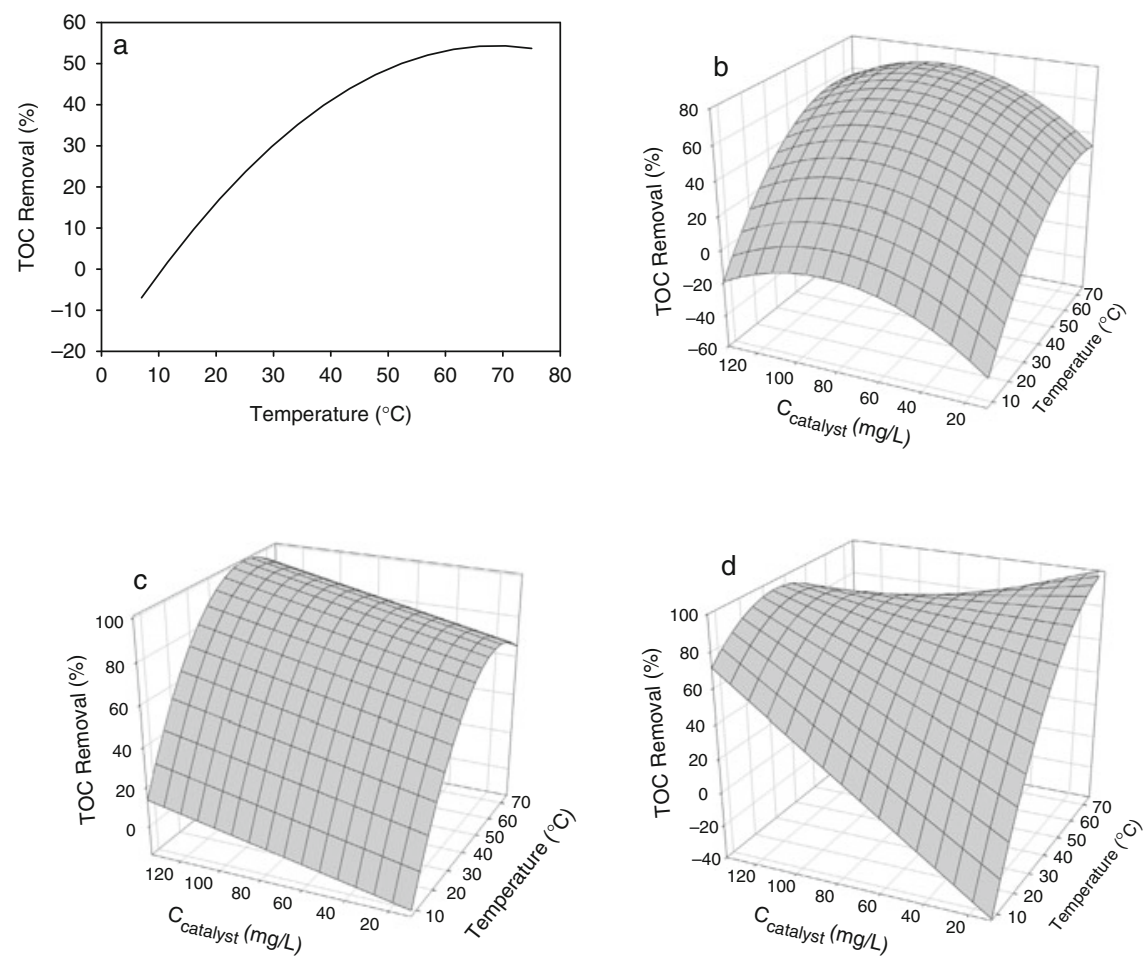

Fig. 6.22 Effect of the process variables in the TOC removal at different reaction times. (a) $1 \mathrm{~h}$, (b) $2 \mathrm{~h}$, (c) $3 \mathrm{~h}$, and (d) $4 \mathrm{~h}$. Reprinted from [26], with permission from American Chemical Society 
quadratic effects obtained with statistical meaning were negative [26], suggesting that optimum values must exist for each parameter, as shown below.

Following the establishment of the semi-empirical models for each response and the subsequent validation against experimental data using commonly employed statistic criteria, one can represent graphically the corresponding surfaces. This can also be done at different reaction times, because the responses considered (color removal $-Y_{1}$, TOC reduction $-Y_{2}$, and iron leaching $-Y_{3}$ ) vary along time (batch reactor operation).

As an example, Fig. 6.22 shows the results obtained in terms of TOC removal for 1-4 h of operation. A significant influence of the temperature, and in some cases of the catalyst concentration, is evident, the process being practically independent of the $\mathrm{H}_{2} \mathrm{O}_{2}$ concentration. For short times the principal variable that affects the TOC removal is the temperature, while for long times the catalyst concentration becomes also important. Thus, in such circumstances the presence of catalyst to improve reaction performance, that is, to obtain a good mineralization degree, is required. Although the highest TOC conversions are achieved at relatively high temperatures, there is an optimal point for TOC removal, which is due to the predominant nonefficient peroxide decomposition. In some cases one can also see an optimum in terms of catalyst concentration, which can be due to a loss of radicals by scavenging reactions in the presence of excess of iron and the formation of iron complexes with organics [26].

Similar plots were obtained for the other responses, which allowed obtaining optimal conditions, at different reaction times [26].

\subsection{Conclusions}

The homogeneous Fenton and Fenton-like processes require complementary steps like precipitation and re-dissolution to prevent water contamination, recover the catalyst, and enable its re-use. This might increase the cost of the processes, not only in terms of supply of chemicals, but also on labor requirements, increasing also the number of process items. So, several attempts have been made to develop efficient supports for the transition metal (namely, iron), so that the resulting catalysts should be catalytically active and stable, in particular making use of pillared clays (PILCs).

Indeed, PILCs represent a diversified range of materials, which can be tailored to achieve success for a particular application. PILCs are attractive as adsorbents, catalysts, or catalyst support due to their high specific surface area, justifying their potential as supports in the Fenton and Fenton-like processes, as described in this chapter, for wastewaters treatment. Besides, these materials can be also produced at large scale, enlarging the interest of use of natural clays for application in catalysis, increasing so the added value of this abundant natural resource.

With the goal of optimizing the Fenton-based processes performance, one should understand what kind of process variables are involved, and what are the expected effects; this has been extensively analyzed along this chapter. However, one should 
also take into account other important technological issues, like catalyst stability. In fact, as a further development in this field, more active and robust catalysts, in which metal leaching is absent, are highly desirable.

For industrial application of these AOPs, the use of continuous flow reactors should be considered, e.g., of the fixed-bed type.

Depending on the type of application envisaged, these AOPs can be considered as a stand-alone process, but more often as a final polishing step or as a preliminary one. In any case, the possible generation of toxic compounds should be investigated and oxidation products formed analyzed.

Finally, for process optimization, statistic-based methodologies proved already to be efficient. However, for scale-up and reactor design, more elaborated phenomenological models are required, which is in part limited by the complexity of the reaction scheme. This could be circumvented with more detailed kinetic studies. Even so, modeling strategies adopted so far have already proved to be of usefulness.

\section{References}

1. Carriazo J, Guelou E, Barrault J, Tatibouët JM, Molina R, Moreno S (2005) Synthesis of pillared clays containing $\mathrm{Al}, \mathrm{Al}-\mathrm{Fe}$ or $\mathrm{Al}-\mathrm{Ce}-\mathrm{Fe}$ from a bentonite: characterization and catalytic activity. Catal Today 107-108:126-132

2. Pera-Titus M, García-Molina V, Baños MA, Giménez J, Esplugas S (2004) Degradation of chlorophenols by means of advanced oxidation processes: a general review. Appl Catal B Environ 47:219-256

3. Andreozzi R, Caprio V, Insola A, Marotta R (1999) Advanced oxidation processes (AOP) for water purification and recovery. Catal Today 53:51-59

4. Malato S, Blanco J, Vidal A, Richter C (2002) Photocatalysis with solar energy at a pilot-plant scale: an overview. Appl Catal B Environ 37:1-15

5. Liotta LF, Gruttadauria M, Di Carlo G, Perrini G, Librando V (2009) Heterogeneous catalytic degradation of phenolic substrates: catalysts activity. J Hazard Mater 162:588-606

6. Sum OSN, Feng J, Hu X, Yue PL (2005) Photo-assisted Fenton mineralization of an azodye acid black 1 using a modified laponite clay-based Fe nanocomposite as a heterogeneous catalyst. Top Catal 33:233-242

7. Najjar W, Azabou S, Sayadi S, Ghorbel A (2007) Catalytic wet peroxide photo-oxidation of phenolic olive oil mill wastewater contaminants. Part I. Reactivity of tyrosol over (Al-Fe)PILC. Appl Catal B Environ 74:11-18

8. Sabhi S, Kiwi, J (2001) Degradation of 2,4-dichlorophenol by immobilized iron catalysts. Water Res 35:1994-2002

9. Feng J, Hu X, Yue PL, Zhu HY, Lu GQ (2003) A novel laponite clay-based Fe nanocomposite and its photo-catalytic activity in photo-assisted degradation of Orange II. Chem Eng Sci 58:679-685

10. Gemeay AH, Mansour IA, El-Sharkawy RG, Zaki AB (2003) Kinetics and mechanism of the heterogeneous catalyzed oxidative degradation of indigo carmine. J Mol Catal A: Chem 193:109-120

11. Ishtchenko VV, Huddersman KD, Vitkovskaya RF (2003) Part 1. Production of a modified PAN fibrous catalyst and its optimization towards the decomposition of hydrogen peroxide. Appl Catal A: Gen 242:123-137

12. Letaief S, Casal B, Aranda P, Martín-Luengo MA, Ruiz-Hitzky E (2003) Fe-containing pillared clays as catalysts for phenol hydroxylation. Appl Clay Sci 22:263-277

13. Tachiev G, Roth JA, Bowers AR (2000) Kinetics of hydrogen peroxide decomposition with complexed and free iron catalysts. Int J Chem Kinet 32:24-35 
14. Neamtu M, Zaharia C, Catrinescu C, Yediler A, Macoveanu M, Kettrup A (2004) Feexchanged $\mathrm{Y}$ zeolite as catalyst for wet peroxide oxidation of reactive azo dye Procion Marine H-EXL. Appl Catal B: Environ 48:287-294

15. Dantas TLP, Mendonça VP, Jose HJ, Rodrigues AE, Moreira RFPM (2006) Treatment of textile wastewater by heterogeneous Fenton process using a new composite $\mathrm{Fe}_{2} \mathrm{O}_{3}$ /carbon. Chem Eng J 118:77-82

16. Sum OSN, Feng J, Hu X, Yue PL (2004) Pillared laponite clay-based Fe nanocomposites as heterogeneous catalysts for photo-Fenton degradation of acid black 1. Chem Eng Sci 59:5269-5275

17. Bobu M, Yediler A, Siminiceanu I, Schulte-Hostede S (2008) Degradation studies of ciprofloxacin on a pillared iron catalyst. Appl Catal B: Environ 83:15-23

18. Gil A, Gandía LM, Vicente MA (2000) Recent advances in the synthesis and catalytic applications of pillared clays. Catal Rev Sci Eng 42:145-212

19. Vicente MA, Bañares-Muñoz MA, Gandía LM, Gil A (2001) On the structural changes of a saponite intercalated with various polycations upon thermal treatments. Appl Catal A: Gen 217:191-204

20. Vaccari A (1999) Clays and catalysis: a promising future. Appl Clay Sci 14:161-198

21. Centi G, Perathoner S (2008) Catalysis by layered materials: a review. Micropor Mesopor Mater 107:3-15

22. Gil A, Korili SA, Vicente MA (2008) Recent advances in the control and characterization of the porous structure of pillared clay catalysts. Catal Rev Sci Eng 50:153-221

23. De León MA, Castiglioni J, Bussi J, Sergio M (2008) Catalytic activity of an iron-pillared montmorillonitic clay mineral in heterogeneous photo-Fenton process. Catal Today 133: 600-605

24. Iurascu B, Siminiceanu I, Vione D, Vicente MA, Gil A (2009) Phenol degradation in water through a heterogeneous photo-Fenton process catalyzed by Fe-treated laponite. Water Res 43:1313-1322

25. Ramirez JH, Costa CA, Madeira LM, Mata G, Vicente MA, Rojas-Cervantes ML, LopezPeinado AJ, Martin-Aranda RM (2007) Fenton-like oxidation of Orange II solutions using heterogeneous catalysts based on saponite clay. Appl Catal B: Environ 71:44-56

26. Ramirez JH, Lampinen M, Vicente MA, Costa CA, Madeira LM (2008) Experimental design to optimize the oxidation of Orange II dye solution using a clay-based Fenton-like catalyst. Ind Eng Chem Res 47:284-294

27. Chen Q, Wu P, Li Y, Zhu N, Dang Z (2009) Heterogeneous photo-Fenton photodegradation of Reactive Brilliant Orange X-GN over iron-pillared montmorillonite under visible irradiation. J Hazard Mater 168:901-908

28. Carneiro PA, Pupo Nogueira RF, Zanoni MVB (2007) Homogeneous photodegradation of C.I. Reactive Blue 4 using a photo-Fenton process under artificial and solar irradiation. Dyes Pigm $74: 127-132$

29. Yip ACK, Lam FLY, Hu X (2005) Chemical-vapor-deposited copper on acid-activated bentonite clay as an applicable heterogeneous catalyst for the photo-Fenton-like oxidation of textile organic pollutants. Ind Eng Chem Res 44:7983-7990

30. Tabet D, Saidi M, Houari M, Pichat P, Khalaf H (2006) Fe-pillared clay as a Fenton-type heterogeneous catalyst for cinnamic acid degradation. J Environ Manage 80:342-346

31. Centi G, Cimino G, Grasso G, Perathoner S, Romeo G, Toscano VG (2001) Catalytic wet $\mathrm{H}_{2} \mathrm{O}_{2}$ oxidation of olive oil mills wastewater: development of a Fe/ZSM-5 catalyst system, CPS, Chemeng/0011003. www.Chemweb.com. Accessed 10 October 2009

32. Tatibouët JM, Guelou E, Fournier J (2005) Catalytic oxidation of phenol by hydrogen peroxide over a pillared clay containing iron. Active species and $\mathrm{pH}$ effect. Top Catal 33:225-232

33. Guélou E, Barrault J, Fournier J, Tatibouët JM (2003) Active iron species in the catalytic wet peroxide oxidation of phenol over pillared clays containing iron. Appl Catal B Environ 44:1-8

34. Barrault J, Abdellaoui M, Bouchoule C, Majesté A, Tatibouët JM, Louloudi A, Papayannakos N, Gangas NH (2000) Catalytic wet peroxide oxidation over mixed (Al-Fe) pillared clays. Appl Catal B Environ 27:225-230 
35. Guo J, Al-Dahhan M (2003) Catalytic wet oxidation of phenol by hydrogen peroxide over pillared clay catalyst. Ind Eng Chem Res 42:2450-2460

36. Catrinescu C, Teodosiu C, Macoveanu M, Brendle JM, Le Dred R (2003) Catalytic wet peroxide oxidation of phenol over Fe-exchanged pillared beidellite. Water Res 37:1154-1160

37. Chirchi L, Ghorbel A (2002) Use of various Fe-modified montmorillonite samples for 4-nitrophenol degradation by $\mathrm{H}_{2} \mathrm{O}_{2}$. Appl Clay Sci 21:271-276

38. Catrinescu C, Neamtu M, Brendlé JM, Garcia MG, Kettrup A (2006) Catalytic wet peroxide oxidation of reactive azo dyes over iron-containing pillared beidellite catalyst. In: Suárez M, Vicente MA, Rives V, Sánchez MJ (eds) Materiales Arcillosos: de la Geología a las Nuevas Aplicaciones, Salamanca, pp 87-98. Sociedad Española de Arcillas, ISBN: 84-689-6471-9

39. Fenton HJH (1894) Oxidation of tartaric acid in presence of iron. J Chem Soc 65:899-910

40. Haber F, Weiss J (1934) The catalytic decomposition of hydrogen peroxide by iron salts. Proc R Soc Lond 147:332-351

41. Lücking F, Köser H, Jank M, Ritter A (1998) Iron powder, graphite and activated carbon as catalysts for the oxidation of 4-chlorophenol with hydrogen peroxide in aqueous solution. Water Res 32:2607-2614

42. Safarzadeh-Amiri A, Bolten JR, Cater SR (1996) The use of iron in advanced oxidation processes. J Adv Oxid Technol 1:18-26

43. Bigda RJ (1995) Consider Fenton chemistry for wastewater treatment. Chem Eng Proc 91: 62-66

44. Walling C (1975) Fenton's reagent revisited. Acc Chem Res 8:125-131

45. Kitis M, Adams CD, Daigger GT (1999) The effects of Fenton's reagent pretreatment on the biodegradability of non-ionic surfactants. Water Res 33:2561-2568

46. Yoon J, Lee Y, Kim S (2001) Investigation of the reaction pathway of OH radicals produced by Fenton oxidation in the conditions of wastewater treatment. Water Sci Technol 44:15-21

47. Lu MC, Lin CJ, Liao CH, Ting WP, Huang RY (2001) Influence of $\mathrm{pH}$ on the dewatering of activated sludge by Fenton's reagent. Water Sci Technol 44:327-332

48. Walling C, Goosen A (1973) Mechanism of the ferric ion catalysed decomposition of hydrogen peroxide: effects of organic substrate. J Am Chem Soc 95:2987-2991

49. De Laat J, Gallard H (1999) Catalytic decomposition of hydrogen peroxide by Fe(III) in homogeneous aqueous solutions: mechanism and kinetic modeling. Environ Sci Technol 33:2726-2732

50. Gallard H, De Laat J (2000) Kinetic modelling of Fe(III)/ $\mathrm{H}_{2} \mathrm{O}_{2}$ oxidation reactions in dilute aqueous solution using atrazine as a model organic compound. Water Res 34:3107-3116

51. Walling C, Kato S (1971) The oxidation of alcohols by Fenton's reagent: the effect of copper ion. J Am Chem Soc 93:4275-4281

52. Lin SH, Lo CC (1997) Fenton process for treatment of desizing wastewater. Water Res 31:2050-2056

53. Luo M, Bowden D, Brimblecombe $\mathrm{P}$ (2009) Catalytic property of $\mathrm{Fe}-\mathrm{Al}$ pillared clay for Fenton oxidation of phenol by $\mathrm{H}_{2} \mathrm{O}_{2}$. Appl Cat B Environ 85:201-206

54. Sanabria N, Alvarez A, Molina R, Moreno S (2008) Synthesis of pillared bentonite starting from the Al-Fe polymeric precursor in solid state, and its catalytic evaluation in the phenol oxidation reaction. Catal Today 133-135:530-533

55. Pignatello J (1992) Dark and photoassisted $\mathrm{Fe}^{3+}$-catalyzed degradation of chlorophenoxy herbicides by hydrogen peroxide. Environ Sci Technol 26:944-951

56. Zazo JA, Casas JA, Mohedano AF, Rodriguez JJ (2006) Catalytic wet peroxide oxidation of phenol with a Fe/active carbon catalyst. Appl Catal B Environ 65:261-268

57. Molina R, Martínez F, Melero JA, Bremner DH, Chakinala AG (2006) Mineralization of phenol by a heterogeneous ultrasound/Fe-SBA- $15 / \mathrm{H}_{2} \mathrm{O}_{2}$ process: multivariate study by factorial design of experiments. Appl Catal B Environ 66:198-207

58. De Laat J, Le TG (2006) Effects of chloride ions on the iron(III)-catalyzed decomposition of hydrogen peroxide and on the efficiency of the Fenton-like oxidation process. Appl Catal B Environ 66:137-146 
59. Pintar A, Levec J (1992) Catalytic oxidation of organics in aqueous solutions: kinetics of phenol oxidation. J Catal 135:345-357

60. Fajerwerg K, Debellefontaine H (1996) Wet oxidation of phenol by hydrogen peroxide using heterogeneous catalysis Fe-ZSM-5: a promising catalyst. Appl Catal B: Environ 10:229-235

61. Fortuny A, Ferrer C, Bengoa C, Font J, Fabregat A (1995) Catalytic removal of phenol from aqueous phase using oxygen or air as oxidant. Catal Today 24:79-83 